Update on the Radiation Code in IMPACT: Clouds, Heating Rates, and Comparisons

T. Edis, K. Grant, P. Cameron-Smith

September 2, 2005 
This document was prepared as an account of work sponsored by an agency of the United States Government. Neither the United States Government nor the University of California nor any of their employees, makes any warranty, express or implied, or assumes any legal liability or responsibility for the accuracy, completeness, or usefulness of any information, apparatus, product, or process disclosed, or represents that its use would not infringe privately owned rights. Reference herein to any specific commercial product, process, or service by trade name, trademark, manufacturer, or otherwise, does not necessarily constitute or imply its endorsement, recommendation, or favoring by the United States Government or the University of California. The views and opinions of authors expressed herein do not necessarily state or reflect those of the United States Government or the University of California, and shall not be used for advertising or product endorsement purposes.

This work was performed under the auspices of the U.S. Department of Energy by University of California, Lawrence Livermore National Laboratory under Contract W-7405-Eng-48. 


\title{
Update on the Radiation Code in IMPACT: Clouds, Heating Rates, and Comparisons
}

\author{
Taner Edis, Keith E. Grant, Philip J. Cameron-Smith
}

This is a summary of work done over two months in the summer of 2005, which was devoted to improving the radiation code of IMPACT, the LLNL 3D global atmospheric chemistry and aerosol model. Most of the work concerned the addition and testing of new cloud optical property routines designed to work with CAM3 meteorological data, and the comparison of CAM3 with the results of IMPACT runs using meteorological data from CAM3 and MACCM3. Additional related work done in the course of these main tasks will be described as necessary.

\section{CAM3 Cloud Properties}

\subsection{New Cloud Routines}

In IMPACT's radiation code, cloud properties are calculated by what are called the cloudopt (for "cloud operator") subroutines. Keith Grant prepared a set of new cloudopt routines intended for use with CAM3 met data. As input, these take in the temperature, the cloud water path, the ice water fraction, surface type (land or ocean/ice/snow), and water-equivalent snow depth. For longwave radiation, and for each wavelength bin of shortwave radiation, these new cloudopt routines output the cloud optical depths, single scattering albedos, and asymmetry factors to be used in the other radiation routines already in place in IMPACT.

The calculations are based on the treatment in the CAM3 GCM. They proceed by obtaining effective radii for liquid and ice water drops, and separately computing longwave cloud optical properties and wavelength-dependent shortwave properties. The shortwave bands in the IMPACT radiation code are different than those used in CAM, so Keith Grant derived the parameters for the IMPACT version of the cloud optical depth parameterization from the same data sources that were used for the CAM GCM for maximum compatibility.. In the longwave, cloud optical depths take the form of

$$
\tau_{l w}=C W P\left[(1-f) \kappa_{l i q}+f\left(\kappa_{i c e}+\frac{1}{r_{i c e}}\right)\right]
$$

where $C W P$ is the cloud water path, $f$ the ice water fraction, $r_{\text {ice }}$ the effective radius, and $\kappa_{\text {liq }}$ and $\kappa_{\text {ice }}$ are constants. In the shortwave, the cloud tau's go as 


$$
\tau_{s w}=C W P\left[(1-f)\left(a_{\text {liq }}+\frac{b_{\text {liq }}}{r_{\text {liq }}}\right)+f\left(a_{\text {ice }}+\frac{b_{\text {ice }}}{r_{\text {ice }}}\right)\right]
$$

for both ice and liquid, weighted by $f$. The wavelength-dependent constants $a$ and $b$ are $a_{\text {liq }} \approx 3 \times 10^{-2} \mathrm{~m}^{2} / \mathrm{g}$ and $a_{\text {ice }} \approx 3 \times 10^{-3} \mathrm{~m}^{2} / \mathrm{g}$, and $b_{\text {liq }} \approx 1 \mu \mathrm{m} \mathrm{m}^{2} / \mathrm{g}$ and $b_{\text {ice }} \approx 2 \mu \mathrm{m} \mathrm{m} / \mathrm{g}$. The values are derived from Slingo, 1989: J. Atmos. Sci. 46(10), 1419-27 for liquid water, and Ebert and Curry, 1992: J. Geophys. Res. 97(D4), 3831-36 for ice water.

In IMPACT, the new routines are in the file cldopt_cam3.F. The existing radiation routines in the phot/swrad directory were modified and streamlined to accommodate the new routines and handle the cloud properties more consistently.

\subsection{Related IMPACT Changes}

The input parameters for the new cloud property routines are available through the CAM3 met data; the ice water fraction is taken to be $f=C I W C /(C I W C+C L W C)$. Currently the water-equivalent snow depth (wesd) is not available in the CAM3 data sets in use. Until it becomes available, wesd $=0$ is used; this only introduces a minor error into the $r_{l i q}$ calculation which can be ignored for testing purposes. When wesd becomes available, IMPACT will have to be modified to read that in along with other CAM3 met data.

For consistency, the name for the cloud water content variable was changed in IMPACT. It used to be that the variable $c l w c$ in IMPACT contained the total water content, $c l w c+c i w c$. Since the CAM3 cloud optical property calculations treat ice and liquid water separately, the name of the previous $c l w c$ was changed to $c w c$, for "cloud water content." Also, when CAM3 is used for radiation calculations, the extra 3D field ciwc is read in and used.

Note: all changes to IMPACT made by Taner Edis in 2005 are in the archive file gem-changes.tar, available in the home directories edis on both the local ASD computers and on seaborg.nersc.gov.

\subsection{Unit Problems with CAM3 Data}

In the original processing of the CAM3 data, the cloud liquid and ice water data was provided in units of $\mathrm{g} / \mathrm{kg}$, though it was mislabeled as $\mathrm{g} / \mathrm{m}^{3}$. IMPACT requires $\mathrm{g} / \mathrm{m}^{3}$. For current purposes, the CAM3 files were post-processed to do the unit conversion. The converted data was written back into the original files, with the names of the $c l w c$ and ciwc fields changed to $c l w c$ fixed and ciwc_fixed. IMPACT was modified to read in the fixed variable names when reading in met data from CAM3. (So any newly created CAM3 files, if their cloud water content units are corrected, should use the new, "fixed" variable names.)

The IDL programs used to make the unit conversions are available on seaborg.nersc.gov, directory edis/runs/TS5. The files are CAM3_fix.pro, which fixes a single file, and CAM3_multifix.pro, which is a sample program for converting a 
set of CAM3 files (such as those for a whole year).

\subsection{Cloud Optical Depth Output}

Two new output variables have been added, written in the radiation (.rad.nc) file produced by IMPACT. When the new namelist variable $p r$ cloud_tau is set to "T" (when pr_rad is also "T"), the variables cloud_tau_sw and cloud_tau_lw are output. This applies to all met data, not just CAM3.

The variable cloud_tau_sw is the wavelength-dependent short wave cloud optical depth. This is a 4D field, with the extra dimension being the wavelength bin (there are 24 in the radiative transfer model). The single long wave cloud optical depth is cloud_tau_lw, a 3D variable. These are in-cloud values, not grid-box averaged! Though IMPACT generally keeps grid-box averaged values for optical depths and so forth, the radiation calculations use in-cloud values, and so these are output for diagnostic purposes.

Note that with CAM3, the in-cloud optical depth values can sometimes be quite large. For example, using the typical $a$ and $b$ coefficients given before, the cloud tau is approximately

$\tau \approx \frac{C W C \Delta z}{f_{c}}\left(a+\frac{b}{r}\right)$

Some not-uncommon values are $C W C=1 \mathrm{~g} / \mathrm{m}^{3}, \Delta z=1000 \mathrm{~m}, f_{c}=0.1, a=10^{-2} \mathrm{~m}^{2} / \mathrm{g}, b=$ $1 \mu \mathrm{m} \mathrm{m}^{2} / \mathrm{g}, r=10 \mu \mathrm{m}$. Then, the order of magnitude for the cloud tau is $\tau \approx 10^{3}$.

Occasional large in-cloud optical depths are, however, not a problem: the reflectance of a cloud behaves roughly like

$$
R \approx \frac{\tau}{7.7+\tau}
$$

(From Lacis and Hansen, 1974: J. Atmos. Sci., 31, 118-33.) So the effect of having an optical depth of, say 500 rather than 50, is insignificant as far as the radiation calculations are concerned.

\section{Comparisons}

\subsection{CAM3 and DAO Cloud Optical Depths}

To get an idea about the kind of cloud optical depths calculated, the results of the new CAM3-based cloud tau parametrization were compared to the DAO-based cloud tau parametrization already in place in IMPACT. The DAO procedure calculates an optical depth based on temperature, and produces results of $\tau=0.16 \Delta p$ for liquid clouds. 


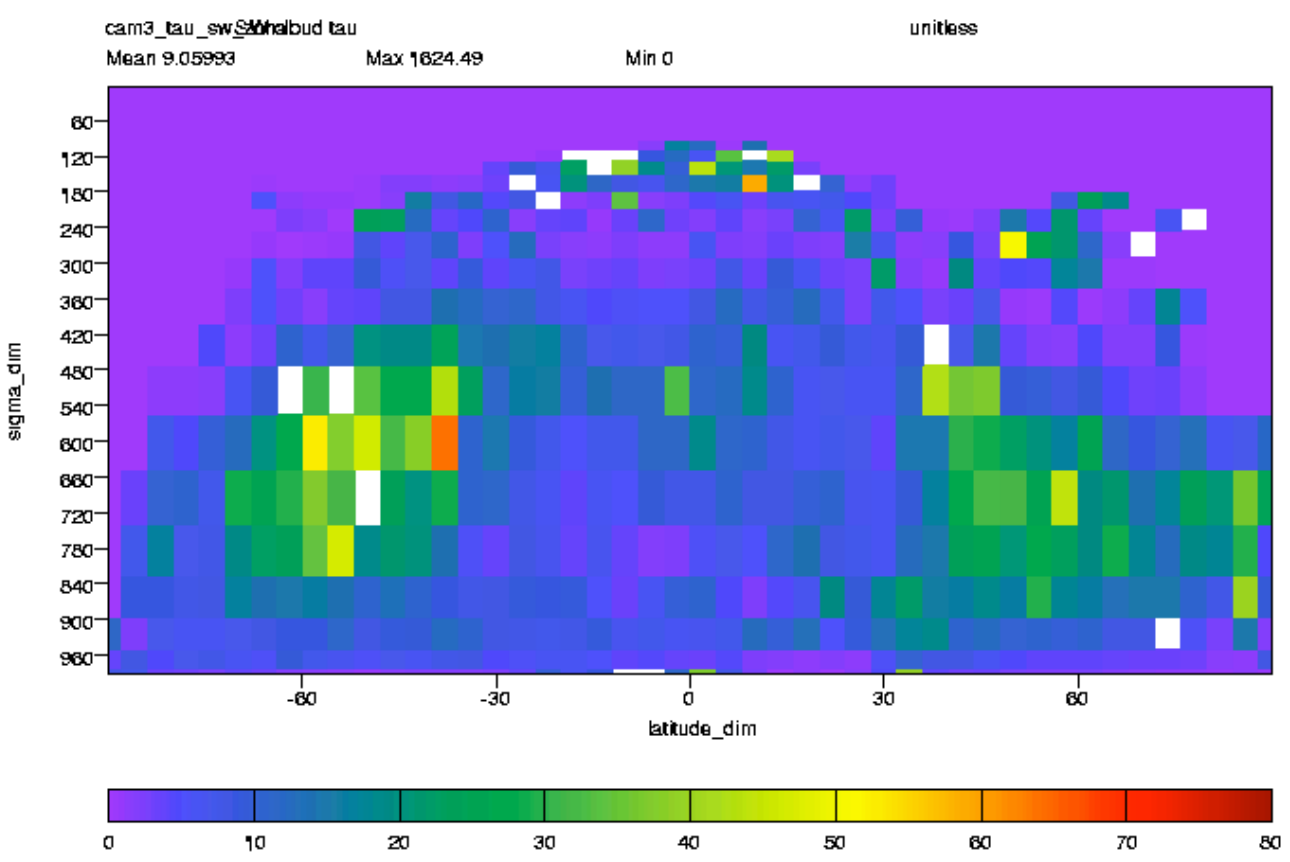

Figure 2.1: CAM3 total cloud optical depths in each grid cell for shortwave radiation, averaged zonally and over wavelength bins. These $\tau$ 's are dimensionless (no units). Some extreme values are evident, with white being off-scale.

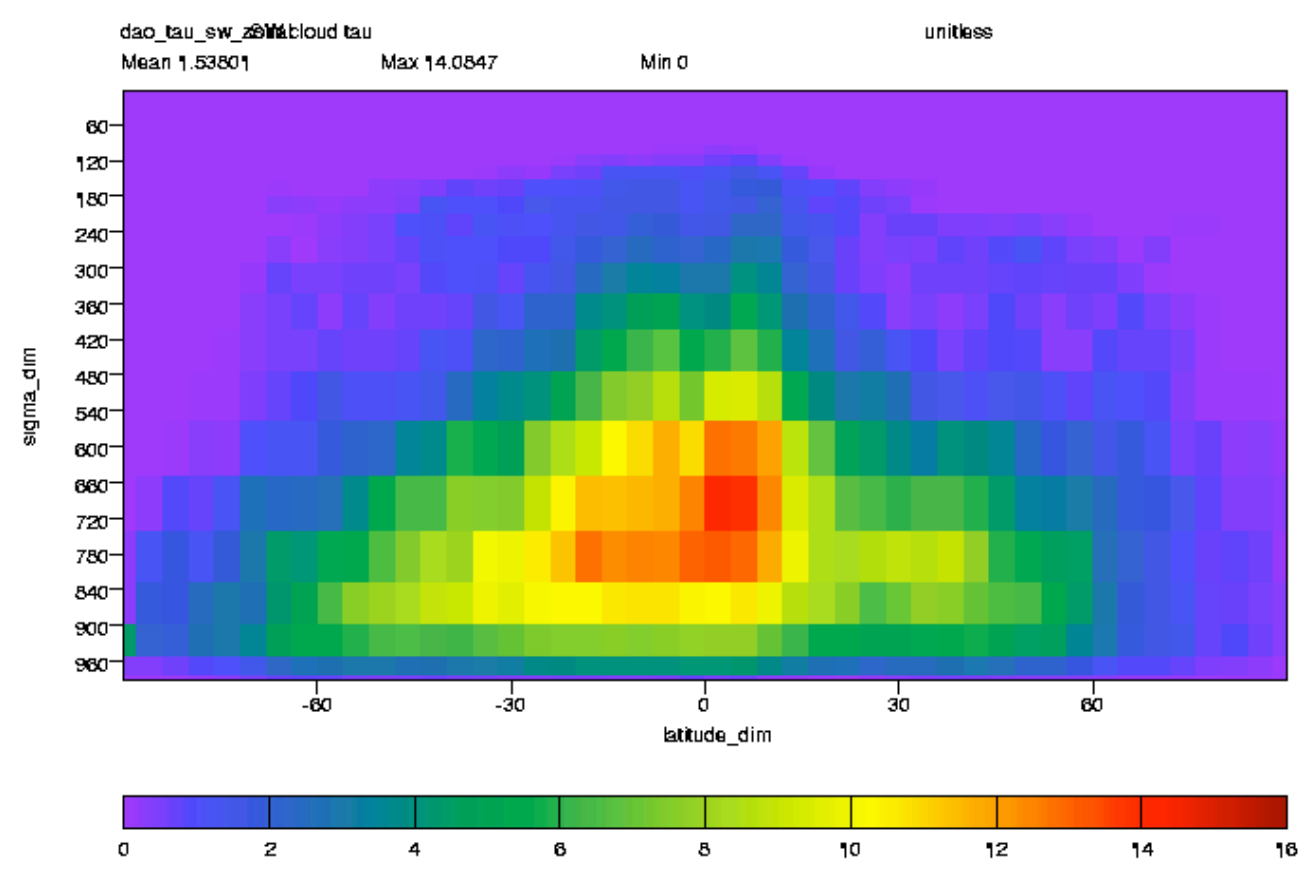

Figure 2.2: DAO total cloud optical depths in each grid cell for shortwave radiation; zonal and wavelength averaged. Unitless. These are smaller that those in Figure 2.1, and distributed differently. 


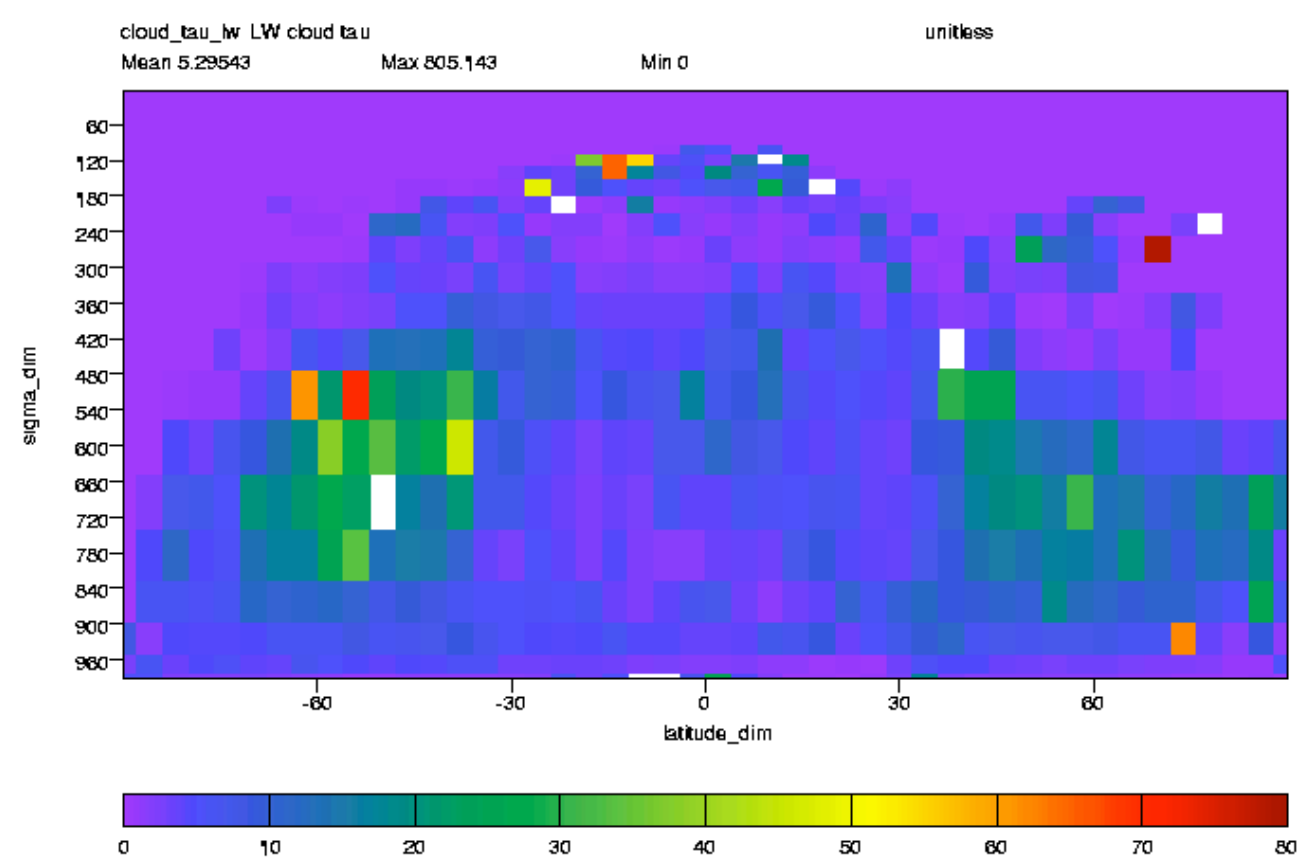

Figure 2.3: CAM3 total cloud optical depths in each grid cell for longwave radiation, zonally averaged. Unitless.

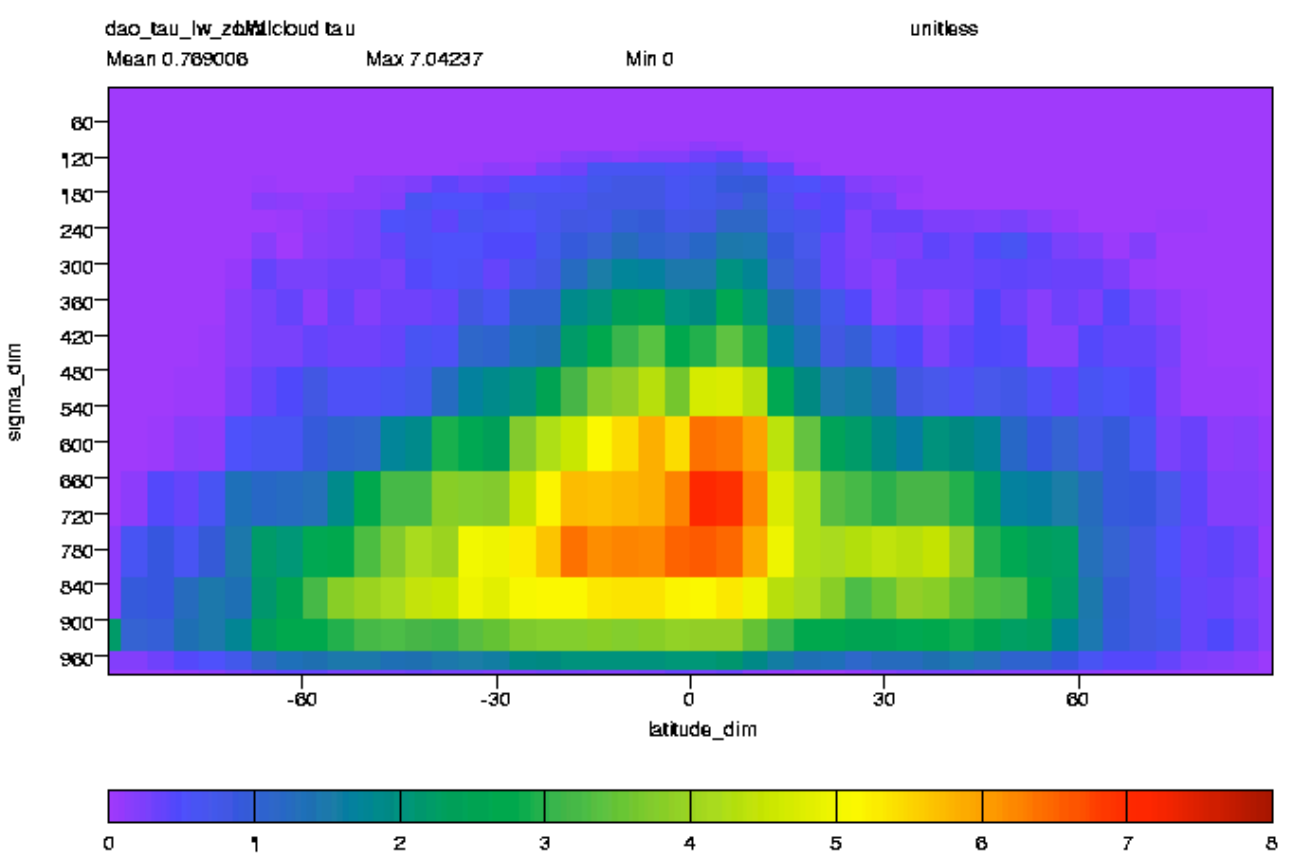

Figure 2.4: DAO total cloud optical depths in each grid cell for longwave radiation, zonally averaged. Unitless. (According to the usual IMPACT approximation for non-CAM3 met data, these are just half those values graphed in Figure 2.2.) 


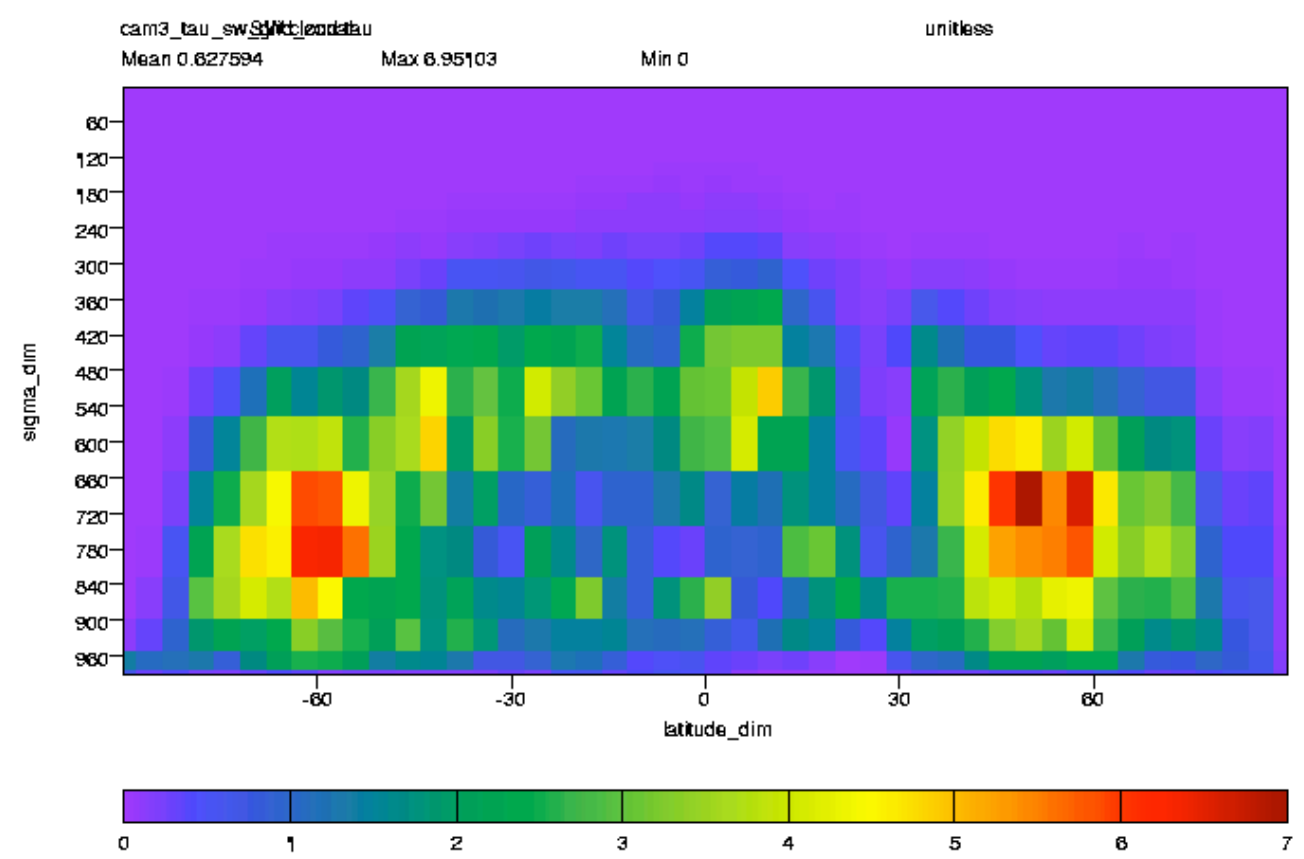

Figure 2.5: CAM3 shortwave cloud optical depths, grid-averaged (Figures 21.-2.5 are in-cloud values; this is included as an extra test). Unitless.

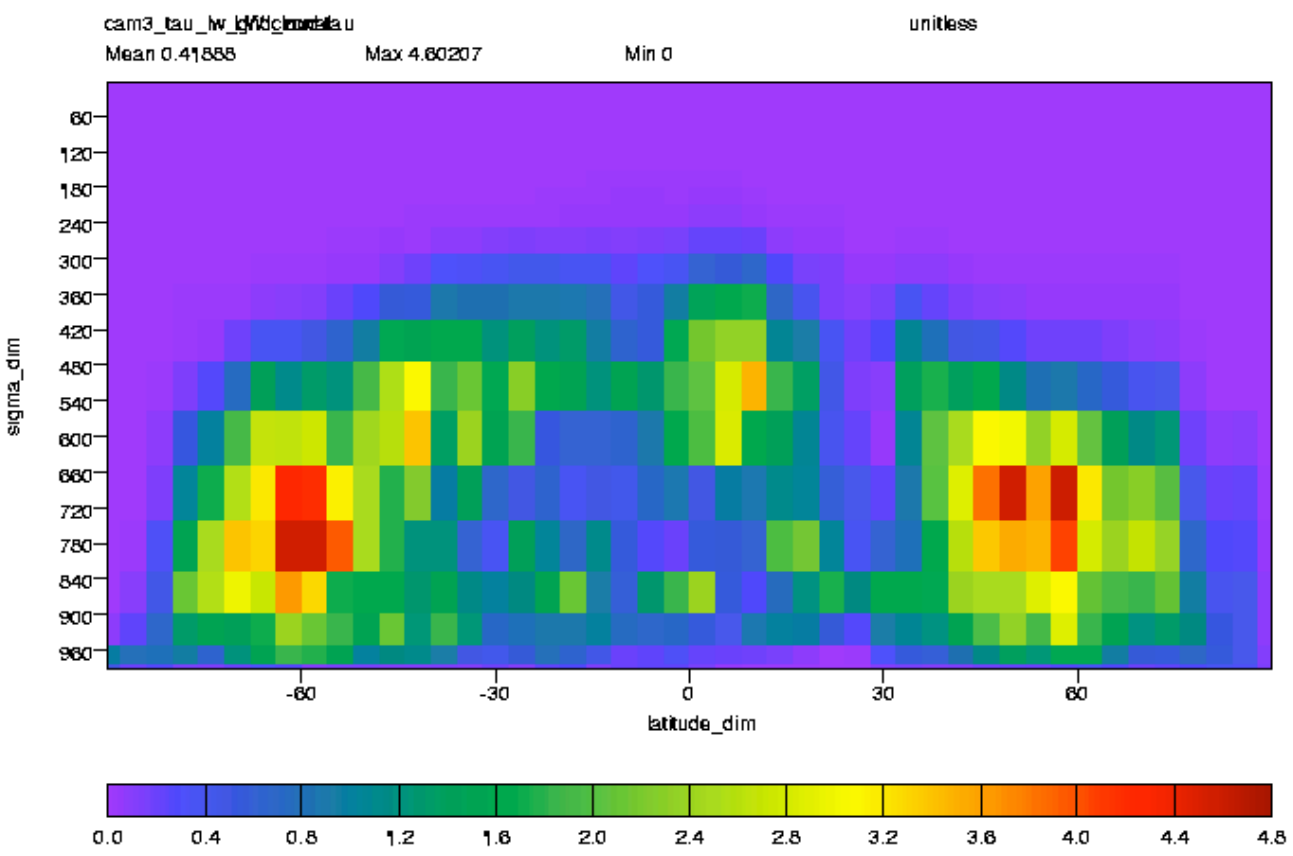

Figure 2.6: CAM3 longwave cloud optical depths, grid-averaged. Unitless. 
The comparisons involved a one-day CAM3 run with initial conditions taken from the test case. The usual radiation calculation runs the new CAM3 procedure to get cloud optical depths. To get a "DAO" run, everything was kept the same, except for a temporary modification in the code which forced a DAO calculation for CAM3 met data. In other words, in the following, everything in the CAM3 and "DAO" runs is identical except for the methods used to calculate the cloud optical properties.

The results show a significant difference in cloud optical depths, not just due to the occasional really large optical depths expected from the CAM3 calculation, but also in the overall, more ordinary values. We have interpreted this discrepancy by observing that the radiation calculations depend not just on in-cloud properties but cloud fractions, and that can be handled quite differently in different met data sets. Hence the overall radiation results should be compared for various runs, to check if the energy balances and over heating rates come out as expected.

Plots of the grid-averaged optical depths are also included; these values for CAM3 seem quite reasonable.

\subsection{CAM3, DAO and MACCM3 Fluxes}

The net top-of-the-atmosphere fluxes for runs with CAM3 and DAO cloud property calculations were also compared, together with the result from a different, full-year MACCM3 run done back in 2004 as part of the ERBE comparison work. In terms of overall pattern, and the global mean values being small (as expected), they are all fairly similar. All results plotted are for 3-hour mean flux values taken around December 31 .

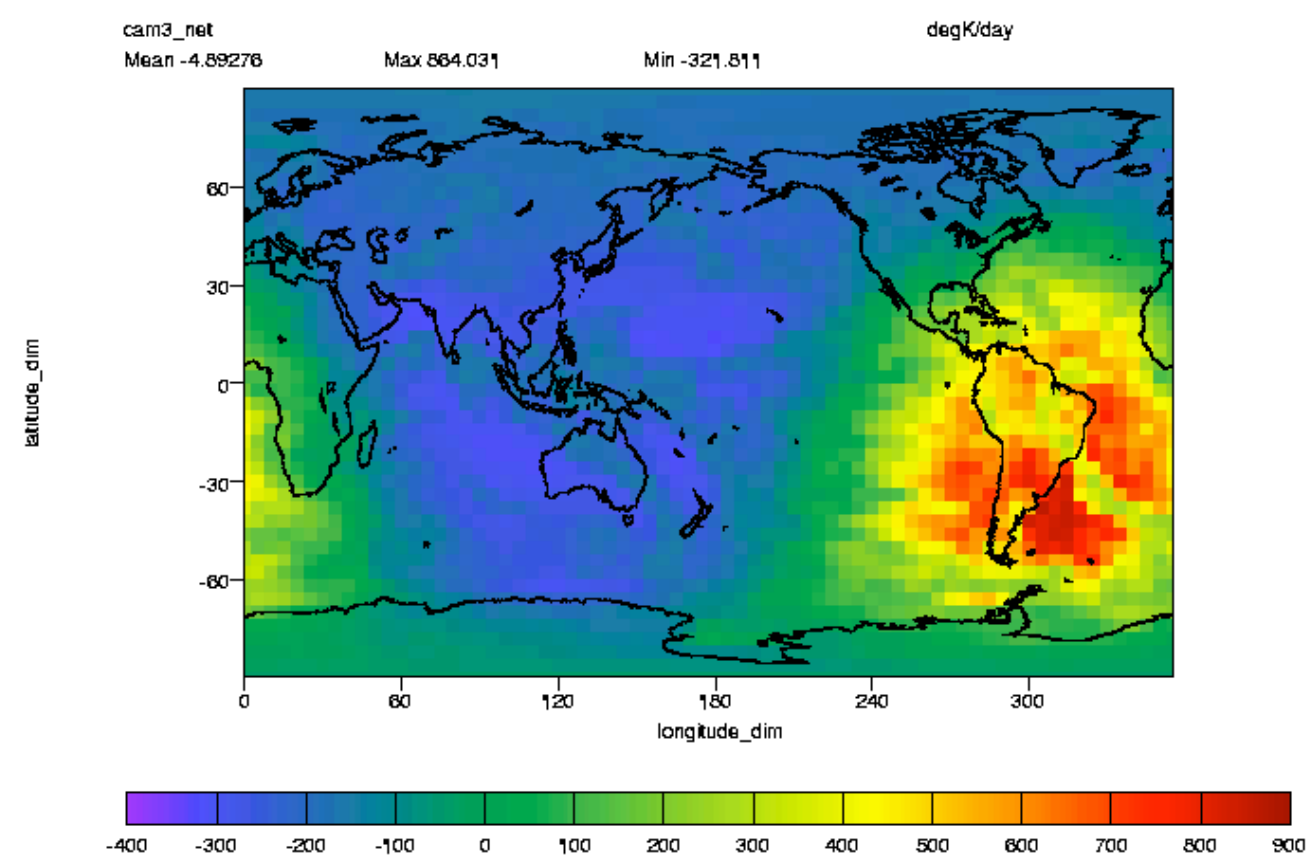

Figure 2.7: TOA net $(\mathrm{SW}+\mathrm{LW})$ flux for CAM3. The units are $\mathrm{W} / \mathrm{m}^{2}$ (vcdat has a bug in unit displays, so the $\operatorname{degK} /$ day above is incorrect). 


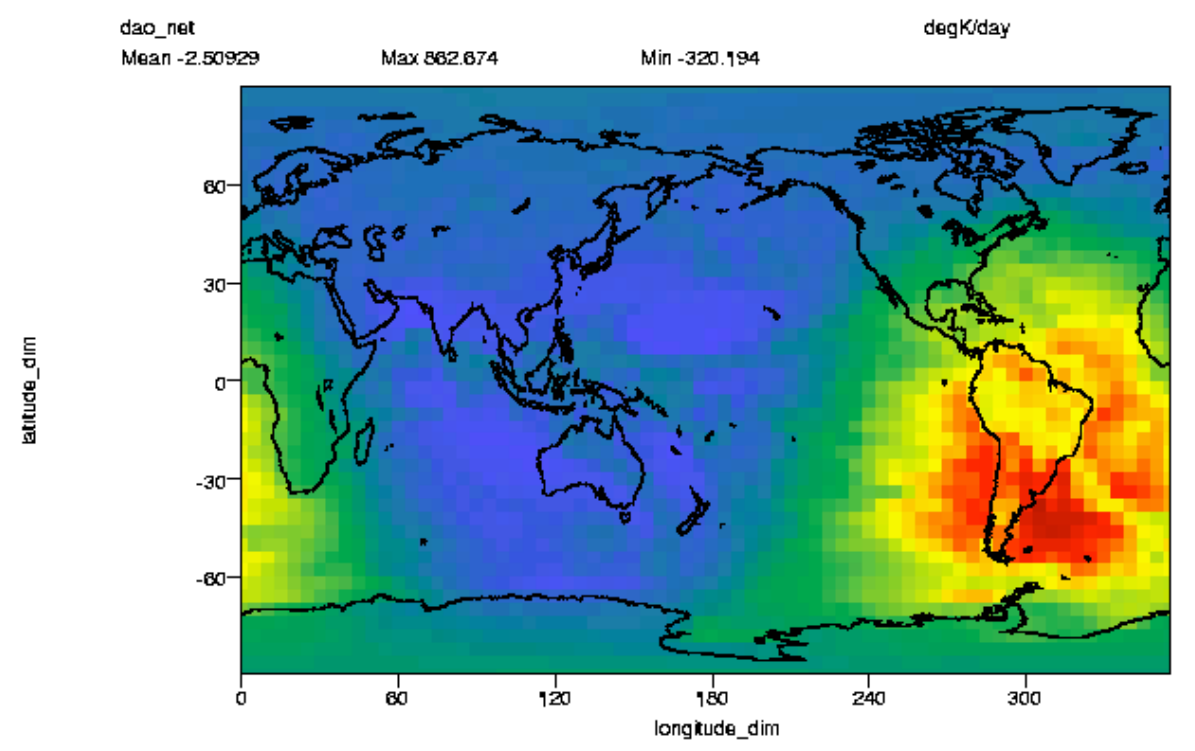

Figure 2.8: TOA net (SW+LW) flux for DAO cloud properties, in $\mathrm{W} / \mathrm{m}^{2}$.

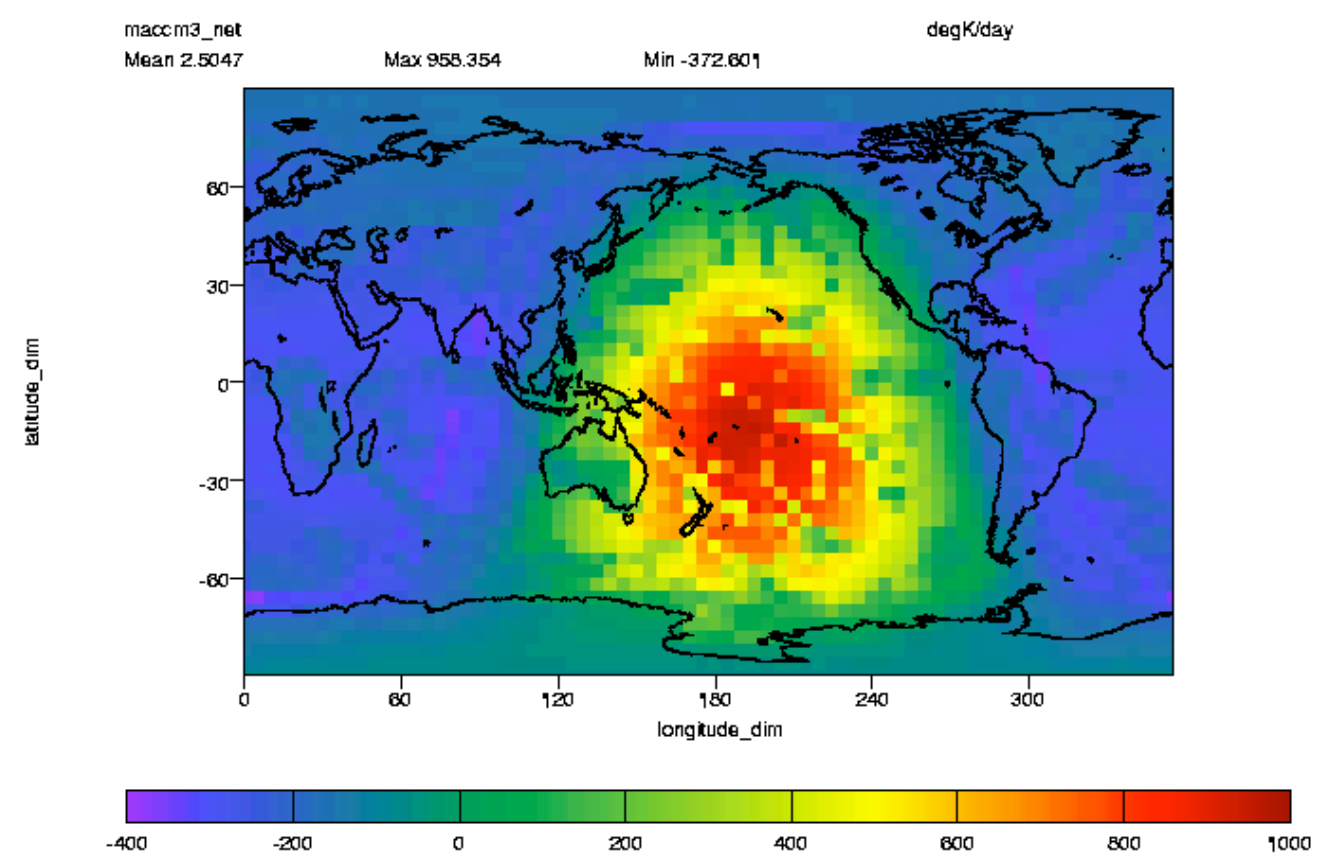

Figure 2.9: TOA net (SW+LW) flux for MACCM3, in $\mathrm{W} / \mathrm{m}^{2}$. Global mean $\sim+2.5 \mathrm{~W} / \mathrm{m}^{2}$; compare to $-5 \mathrm{~W} / \mathrm{m}^{2}$ and $-2.5 \mathrm{~W} / \mathrm{m}^{2}$ in figures 2.7 and 2.8. All are acceptably small. 


\subsection{Heating Rates for CAM3, DAO, and MACCM3}

The heating rates for CAM3 with the CAM3 cloud property routines, CAM3 with DAO cloud properties, and MACCM3 were also of interest. These were compared for the same runs producing the cloud tau and TOA flux graphs presented in the previous figures (one-day run for CAM3, with the test case initial conditions.)

All three heating rate profiles were broadly similar, and especially for CAM3 and MACCM3 followed general patterns expected due to cloud distribution etc. However, one feature of note is the non-zero total heating rate in the region of the tropopause, particularly pronounced in the about $0.5 \mathrm{~K} /$ day observed with the CAM3 run. The excess heating is due to longwave heating.

This is not a very large value, yet it is significant. Evidently, IMPACT's temperature in the tropopause is too cool according to the radiation calculations. Since the radiation code is diagnostic only, there is no feedback and adjustment of the temperature as in a GCM.

Note, however, that in monthly means calculated after IMPACT has been spun up, the excess heating is not as noticeable. We do not know the exact reason, other than observing that the snapshots presented here will naturally have stronger fluctuations than in monthly means. See section 3 . 


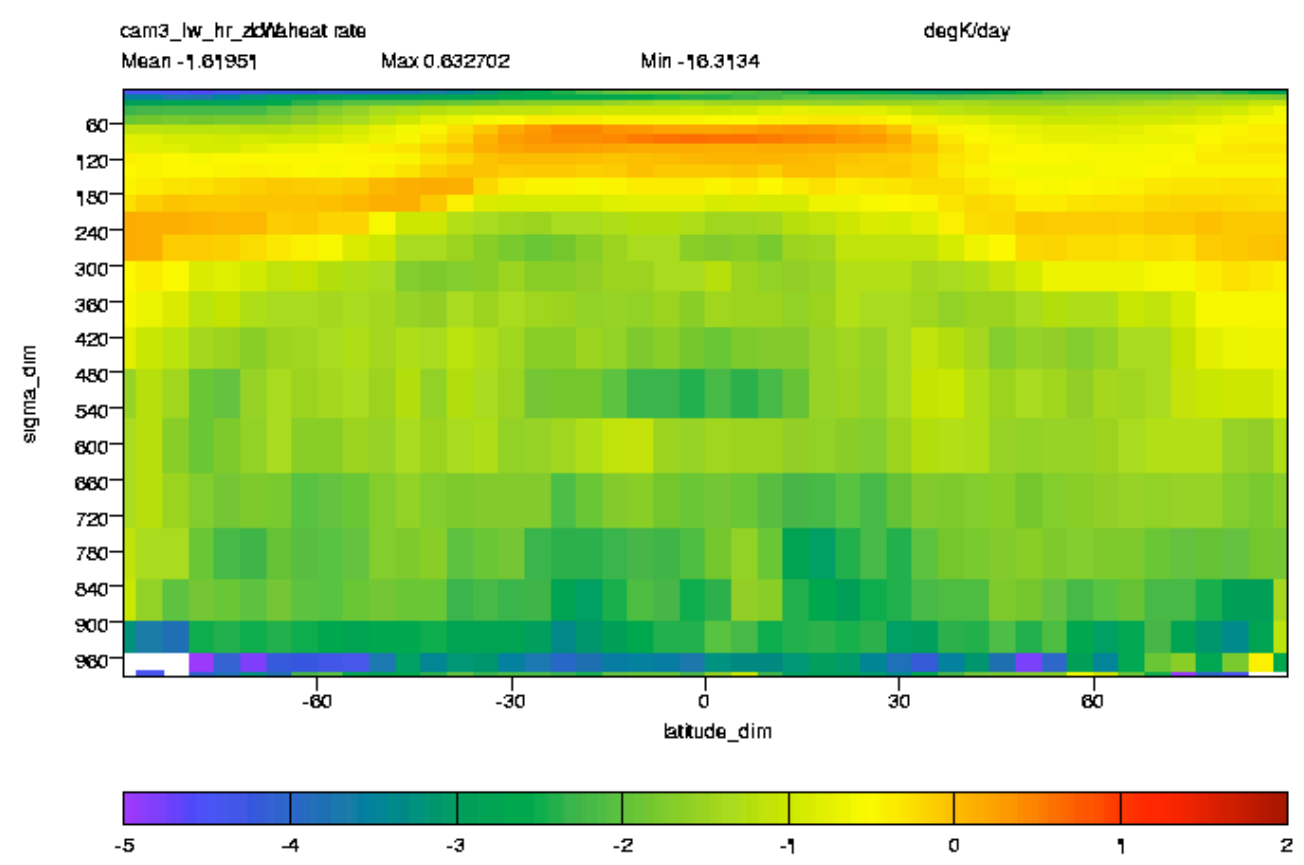

Figure 2.10: CAM3 longwave heating rate, zonally averaged (K/day). Note heating in the region of the tropopause.

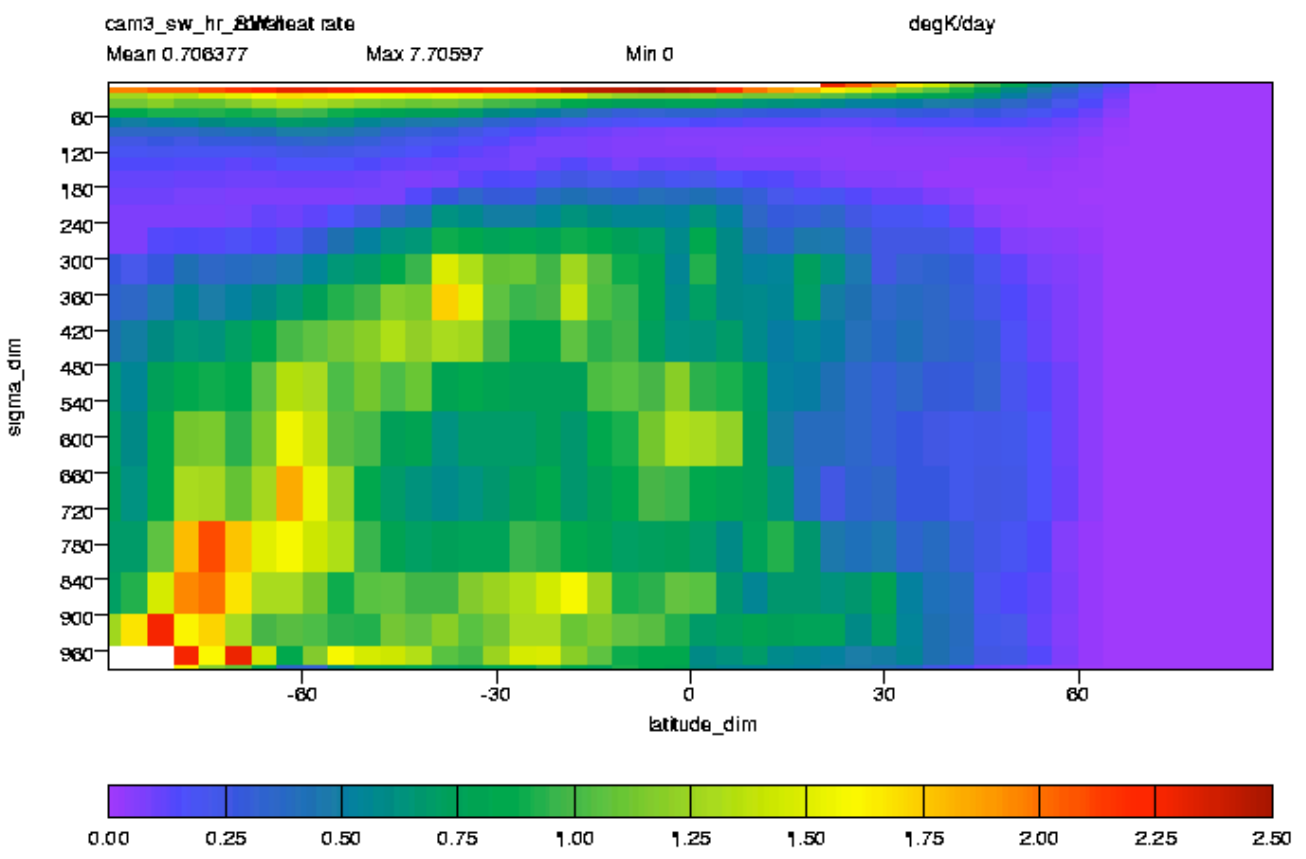

Figure 2.11: CAM3 shortwave heating rate, zonally averaged (K/day). The expected heating in the stratosphere and that due to clouds are visible, but no heating is taking place around the tropopause. 


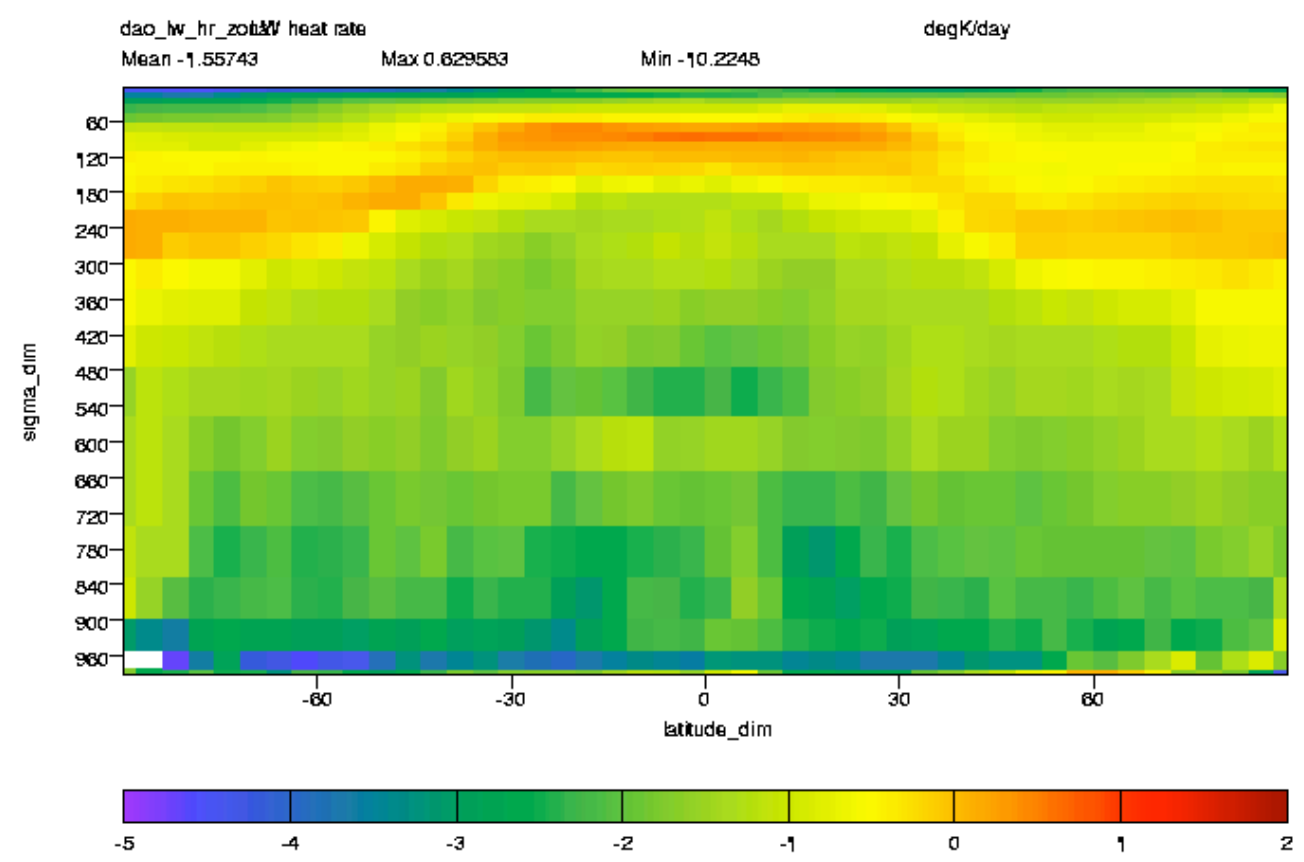

Figure 2.12: Zonally averaged longwave heating rates (K/day) with the DAO cloud property calculation. Very similar to CAM3.

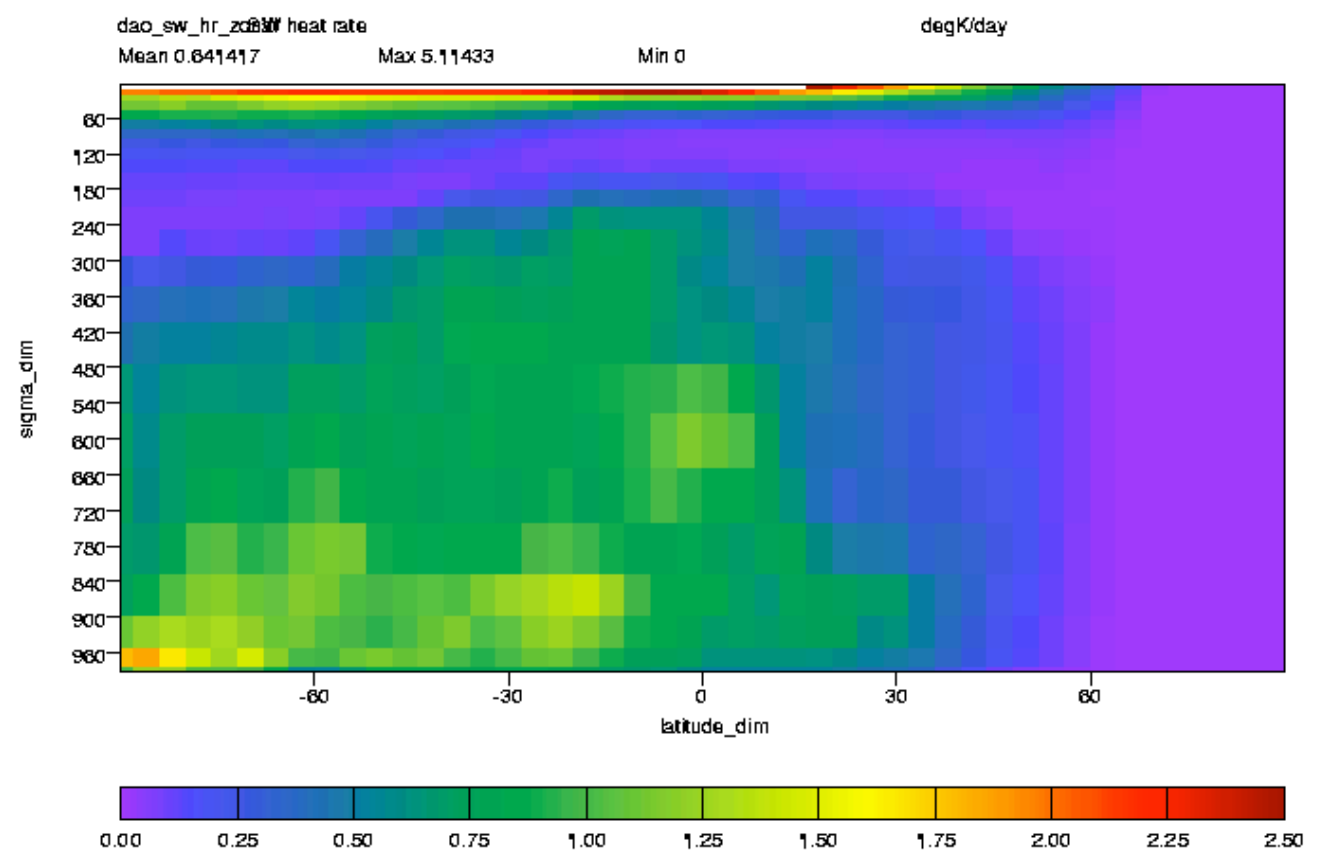

Figure 2.13: Zonally averaged shortwave heating rates (K/day) with "DAO" cloud properties. 


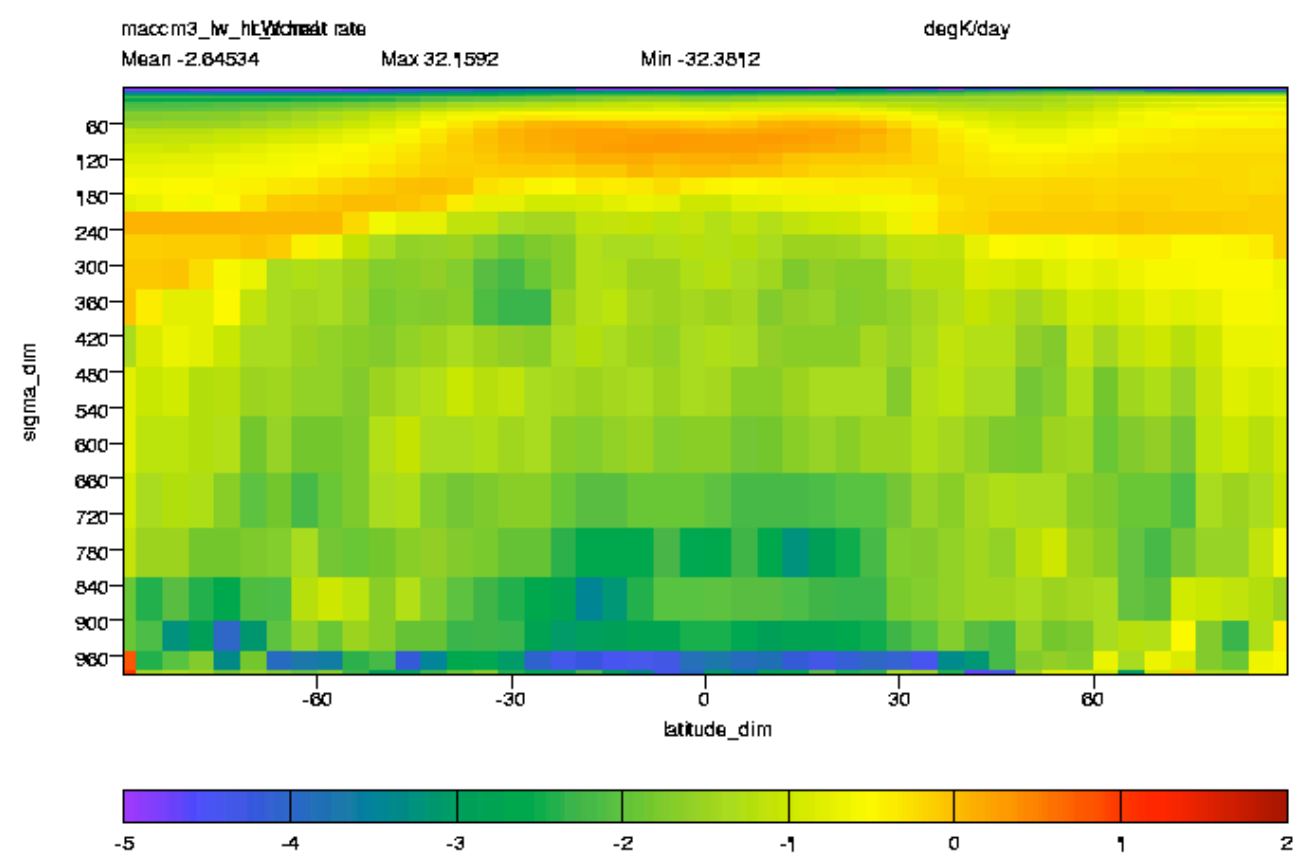

Figure 2.14: Zonally averaged longwave heating rates (K/day) for the MACCM3 run. There is still heating in the tropopause region, but much less than for CAM3.

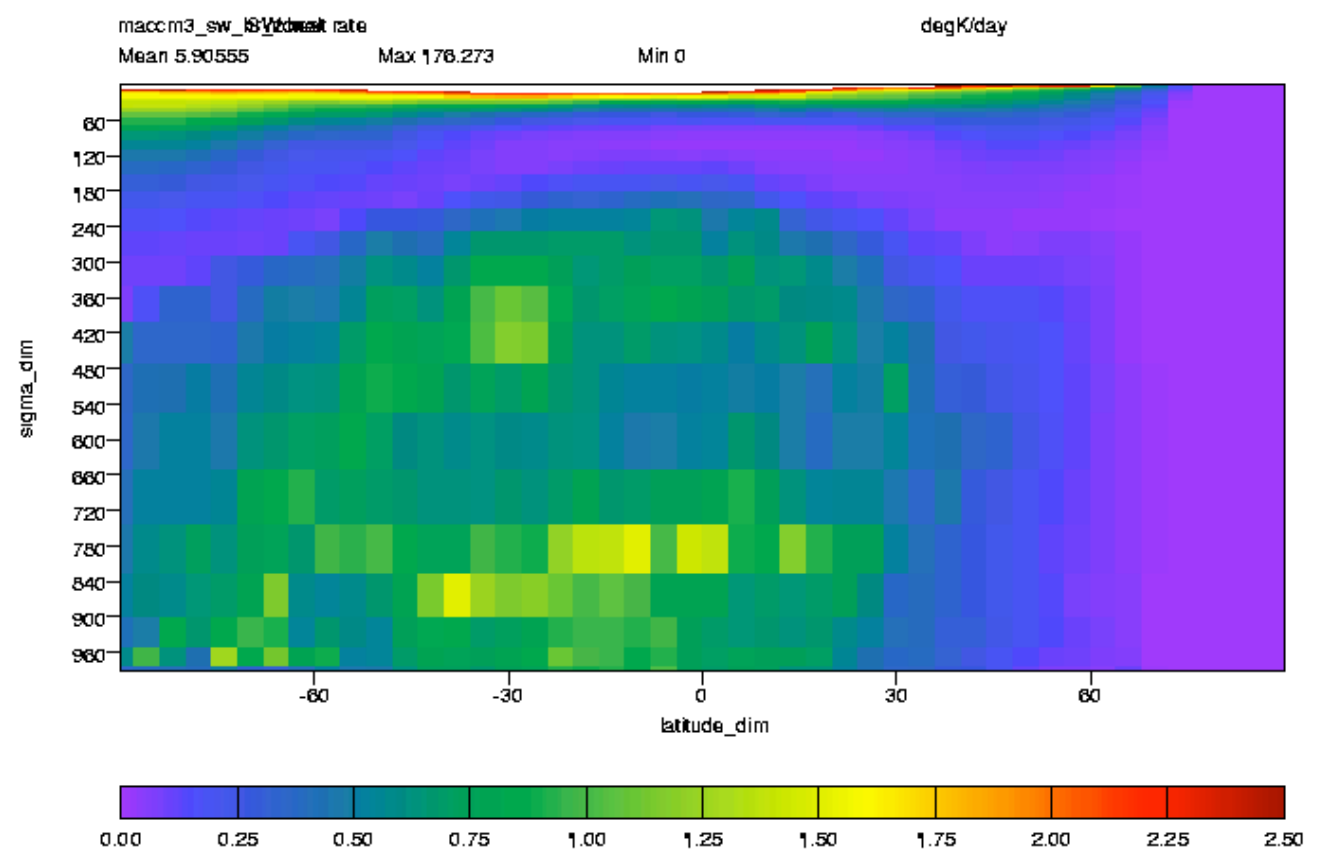

Figure 2.15: Zonally averaged shortwave heating rates $(\mathrm{K} /$ day) for MACCM3. 


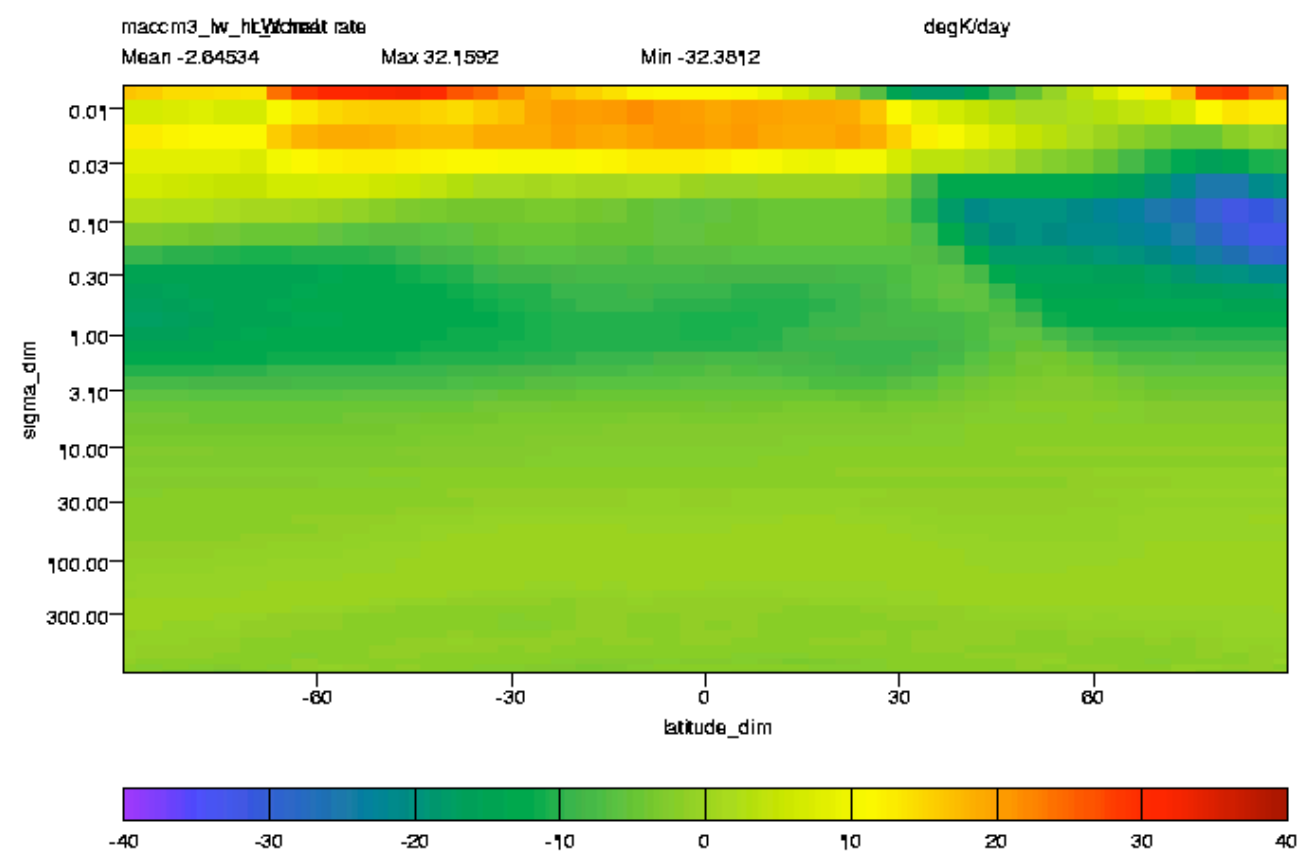

Figure 2.16: MACCM3 longwave heating rate (K/day), with pressure axis plotted on a $\log$ scale.

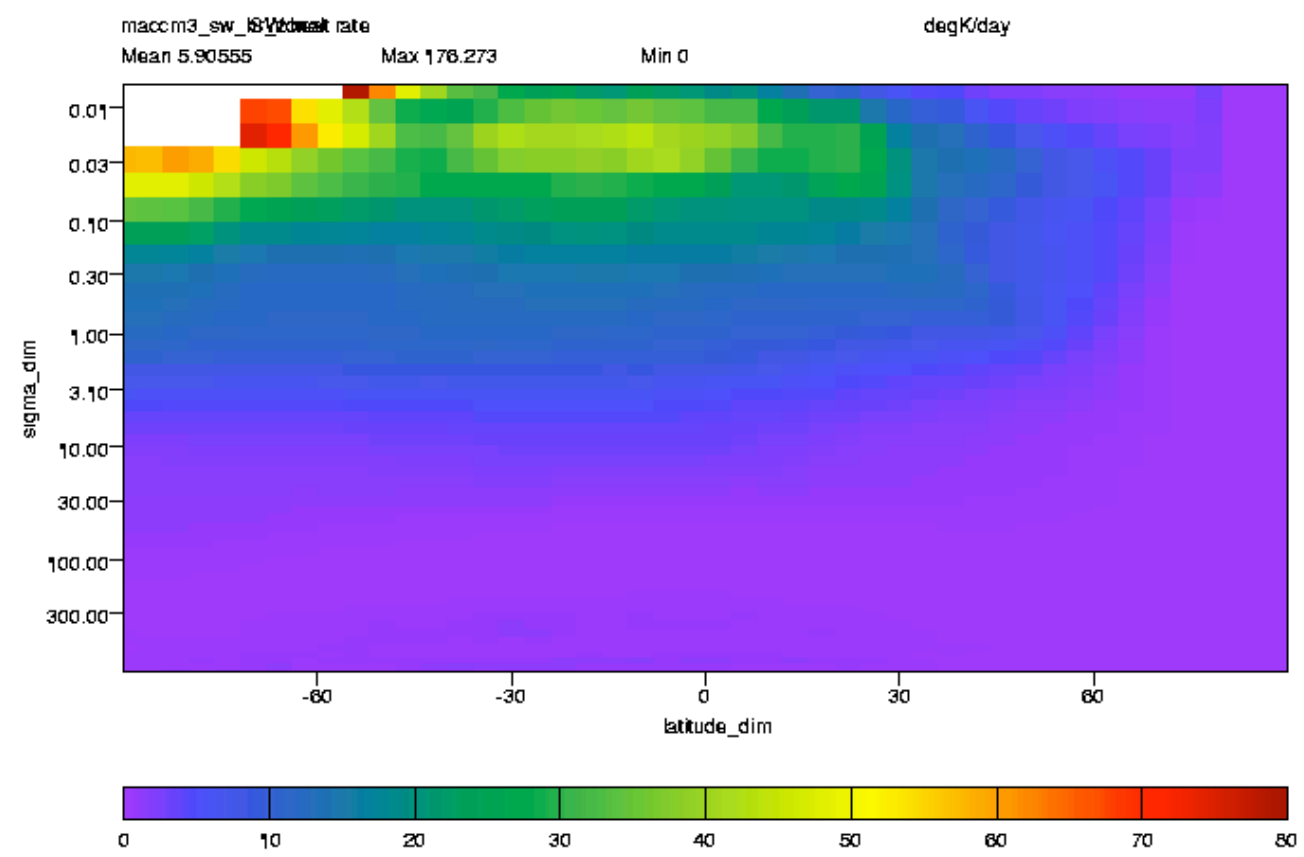

Figure 2.17: MACCM3 shortwave heating rate (K/day) on a vertical log scale. 

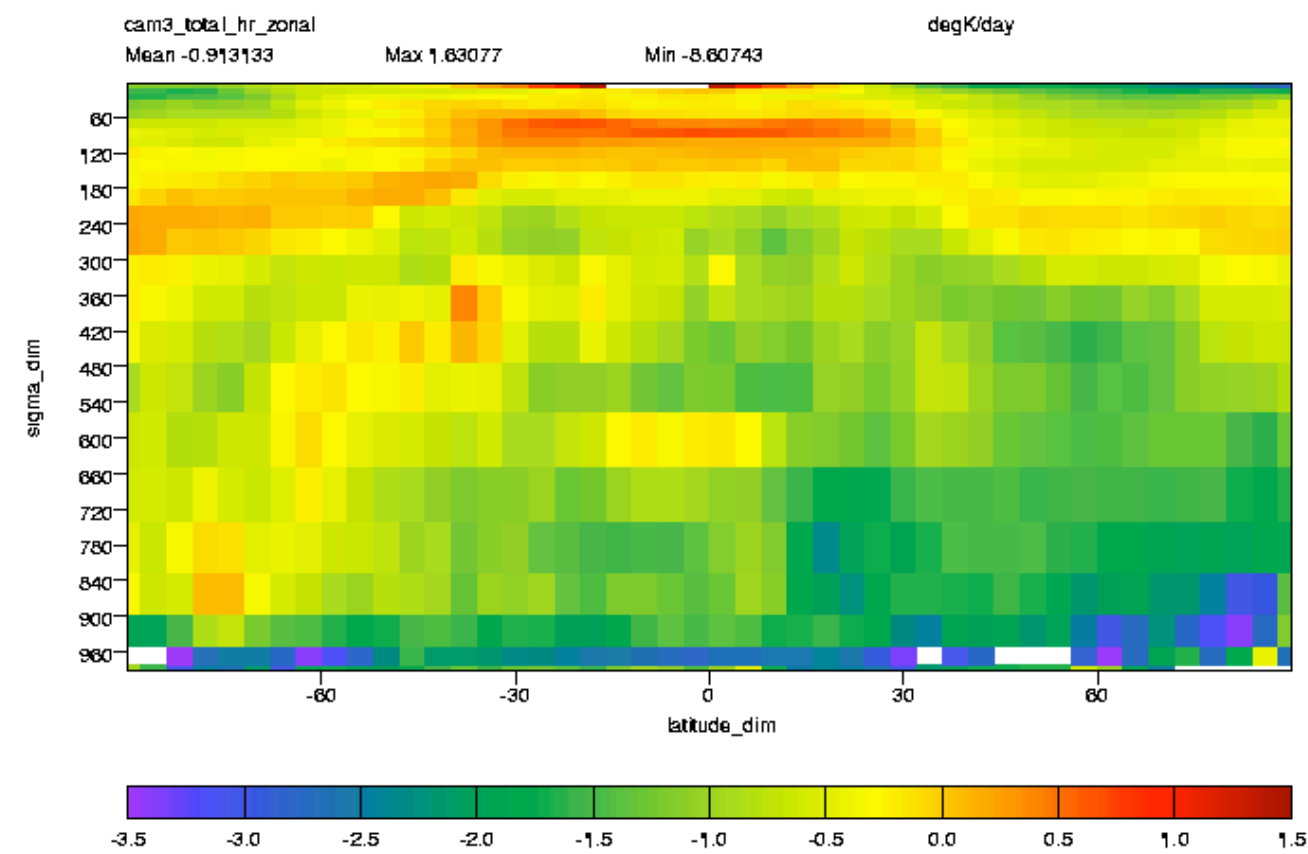

Figure 2.18: Total $(\mathrm{SW}+\mathrm{LW})$ heating rate $(\mathrm{K} /$ day) for CAM3.

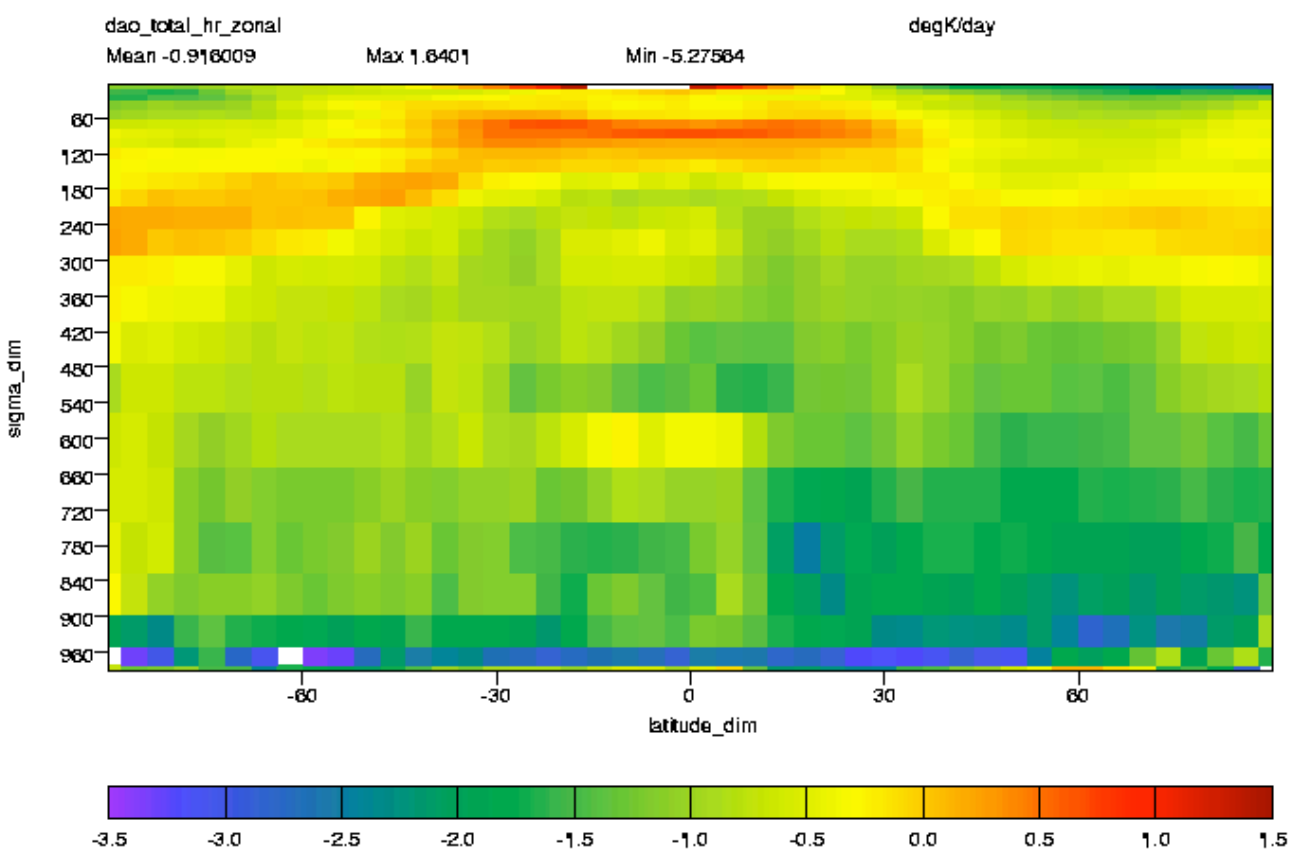

Figure 2:19: Total $(\mathrm{SW}+\mathrm{LW})$ heating rate $(\mathrm{K} /$ day) for DAO calculation of cloud properties. 


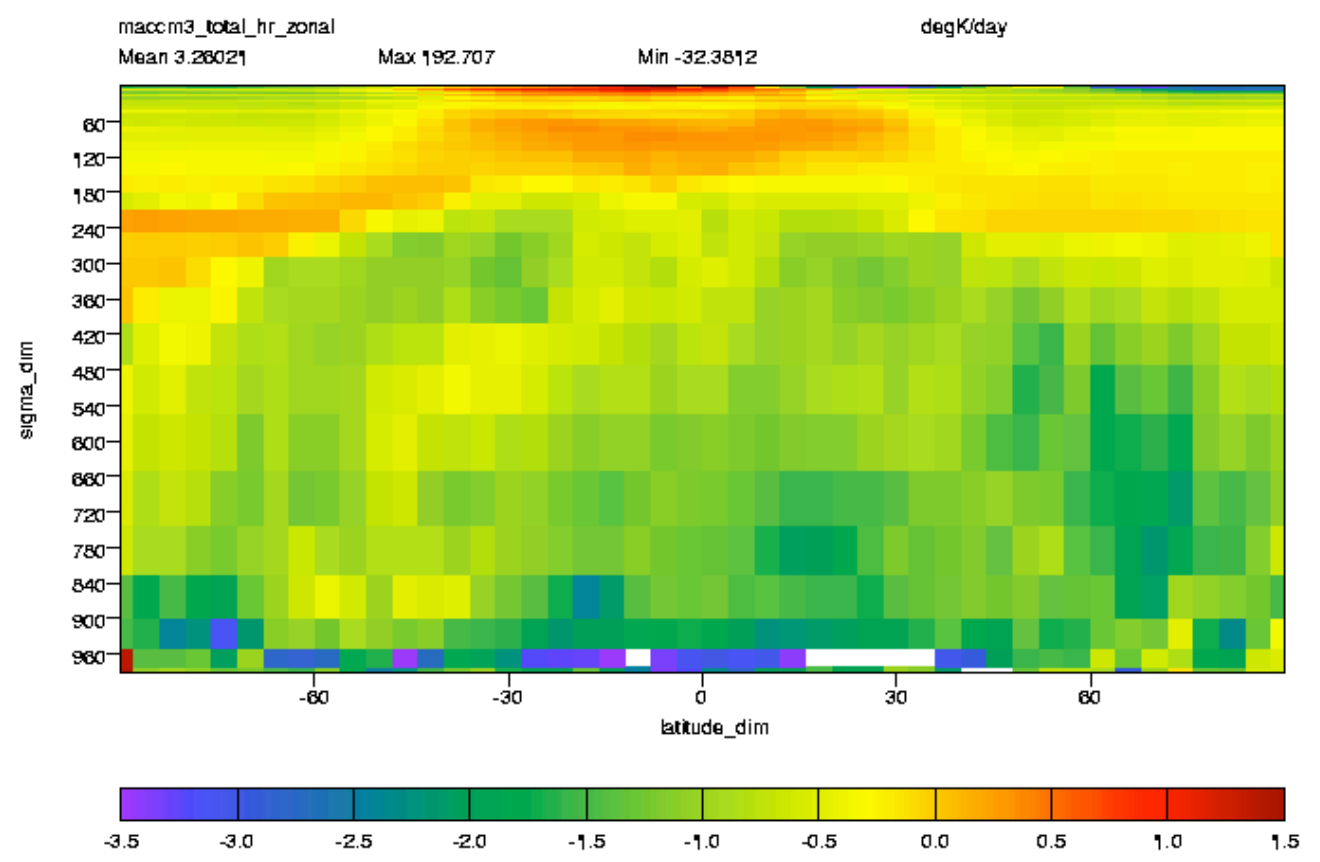

Figure 2.20: Total (SW+LW) heating rate (K/day) for MACCM3.

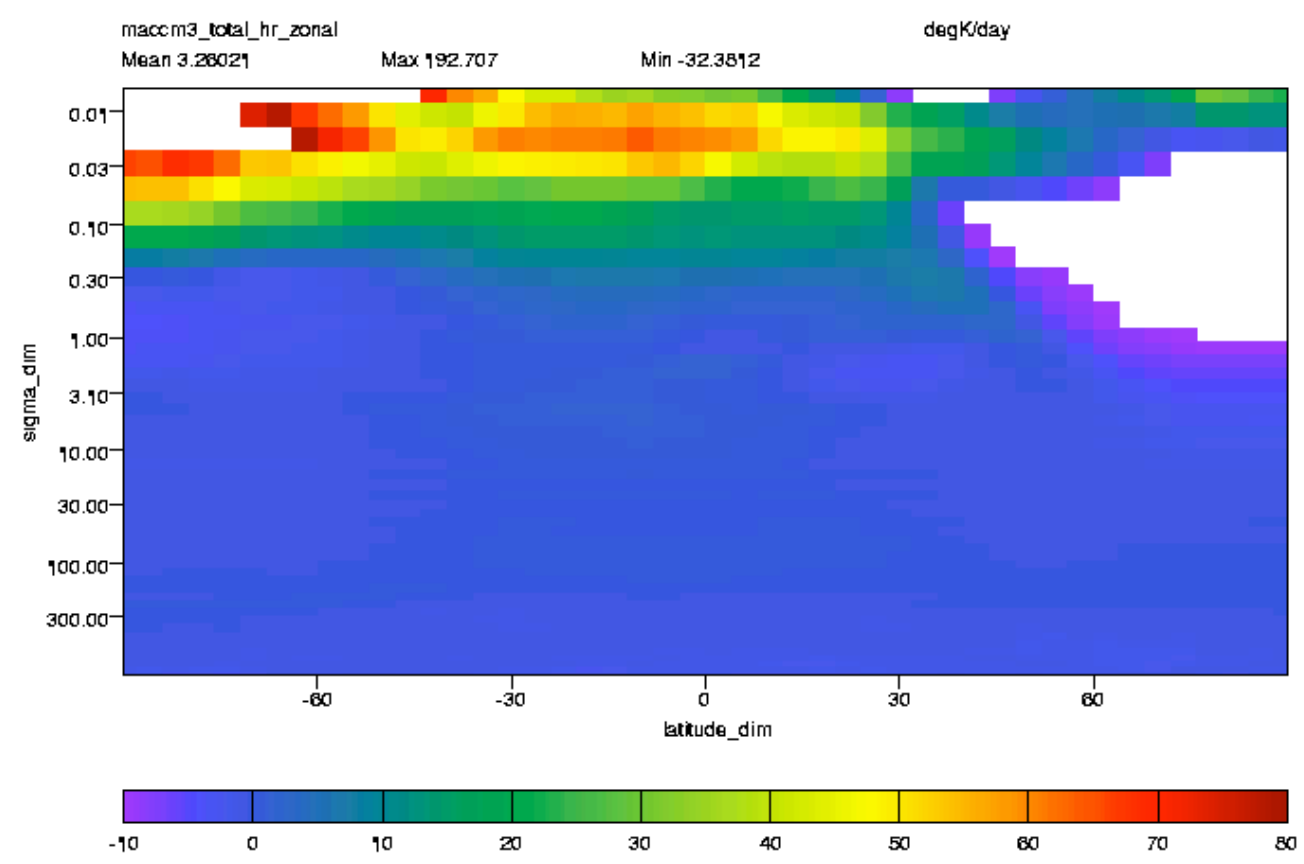

Figure 2.21: Total $(\mathrm{SW}+\mathrm{LW})$ heating rate $(\mathrm{K} /$ day) for MACCM3, log vertical scale. The slight heating in the tropopause is not very noticeable with this color scale, but it is there. 


\section{CAM3 Monthly Mean Radiation Comparisons}

Comparisons between three monthly-mean radiation results:

1. From the CAM3 GCM itself. Data for February was available, though not the same year and clouds as for the IMPACT runs.

2. IMPACT run with CAM3, with a full years' worth of month mean radiation outputs. This was obtained after a 12-month spin-up run based on the CAM3 test case initial conditions, so it should be well spun up. Comparisons here are done with February.

3. IMPACT run with MACCM3. (This is a new run, not the same one used in section 2.) We were only able to obtain 9 months because of a so-far unexplained bug that developed on seaborg (the FORTRAN compiler changed in the middle of our series of runs). February, however, is available, and that is used here. The MACCM3 run was also done after a 12-month spin-up, starting from a vertical regridding of the same initial conditions as for the CAM3 run.

\subsection{Heating Rates}

These compare very well, though there still appears to be a slight heating tendency in the region of the tropopause in all three cases (Figures 3.7, 3.8, 3.9).

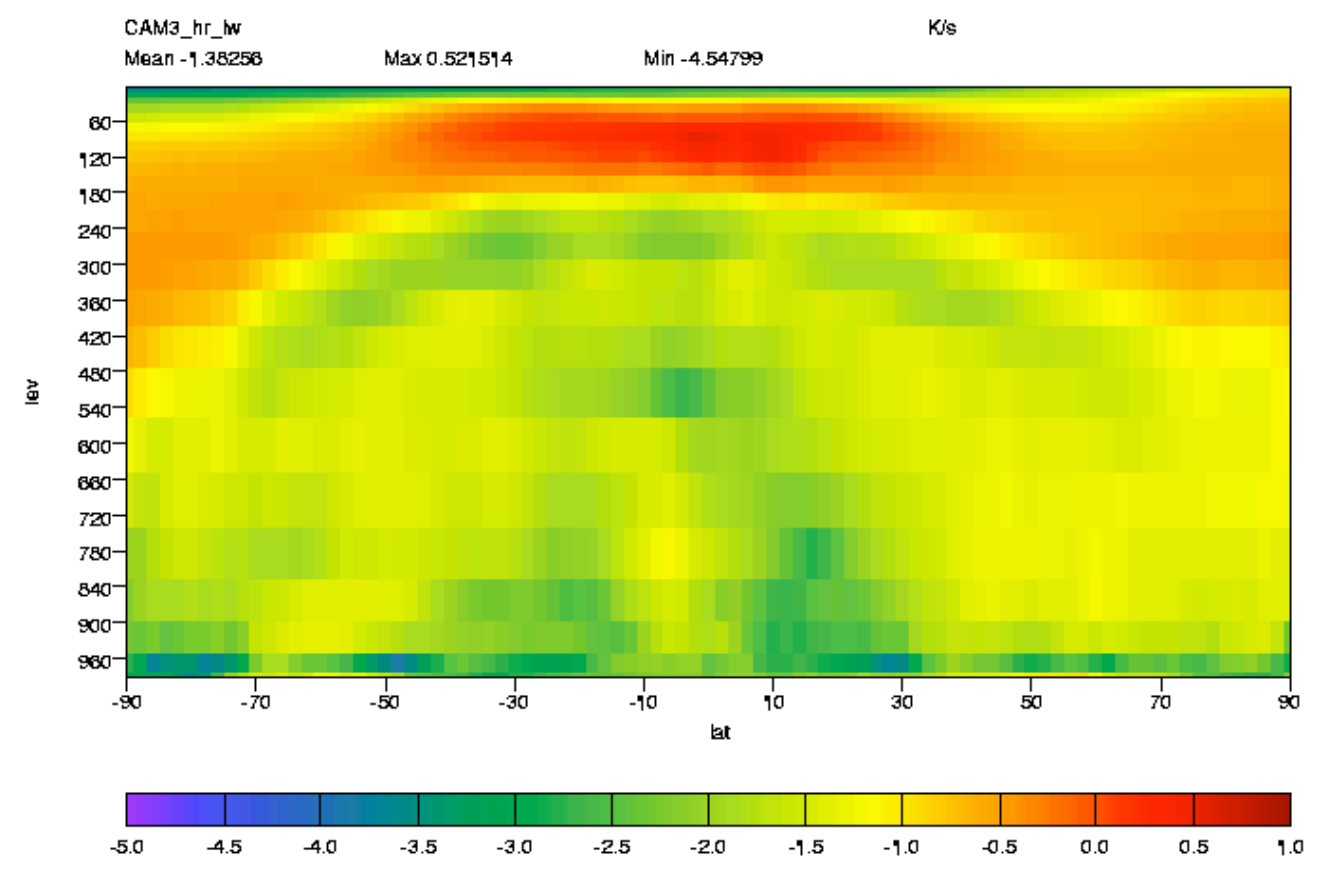

Figure 3.1: CAM3 GCM longwave heating rate, zonally averaged, monthly average for February. Though the graph says $\mathrm{K} / \mathrm{s}$, the units have actually been converted to K/day for comparison with IMPACT outputs. 


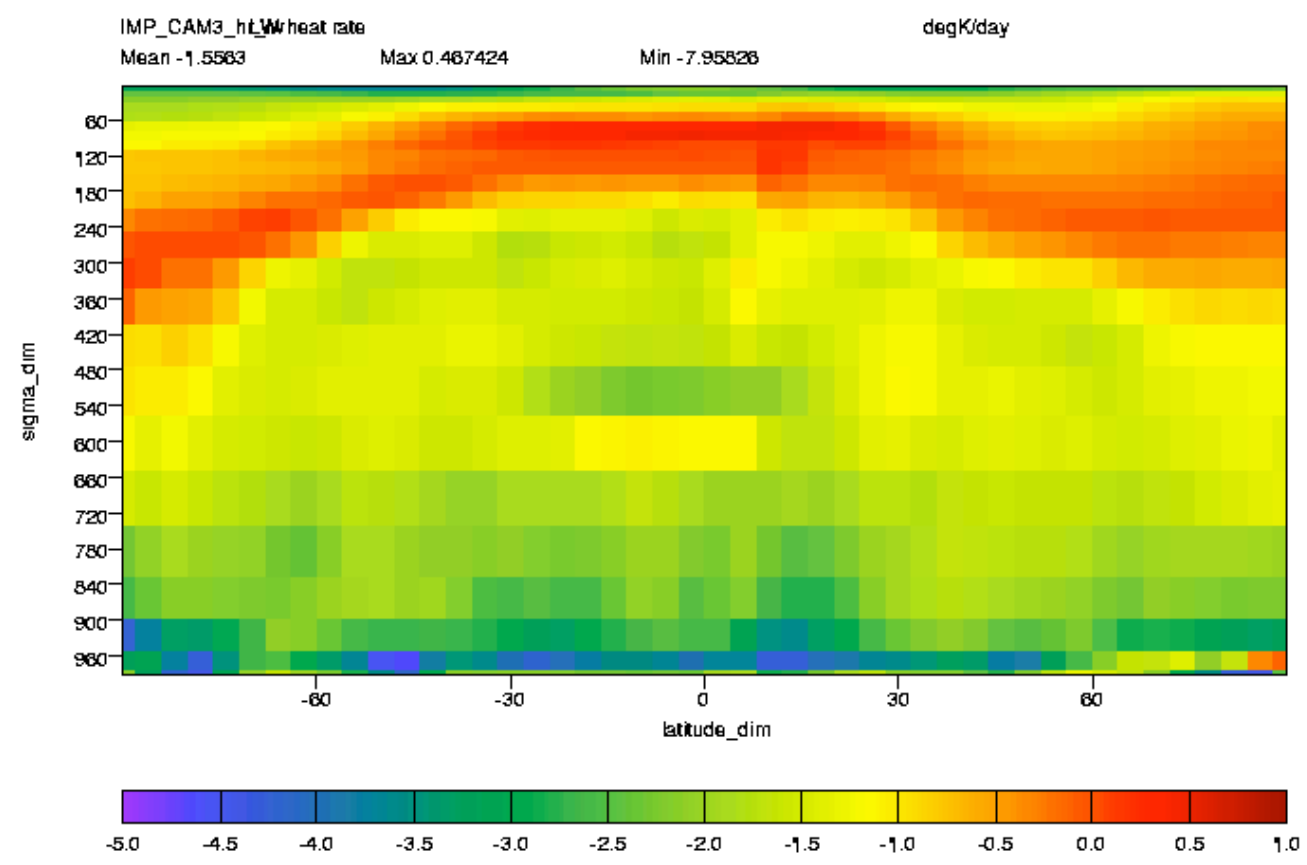

Figure 3.2: IMPACT run with CAM3, zonally averaged February longwave heating rate (K/day).

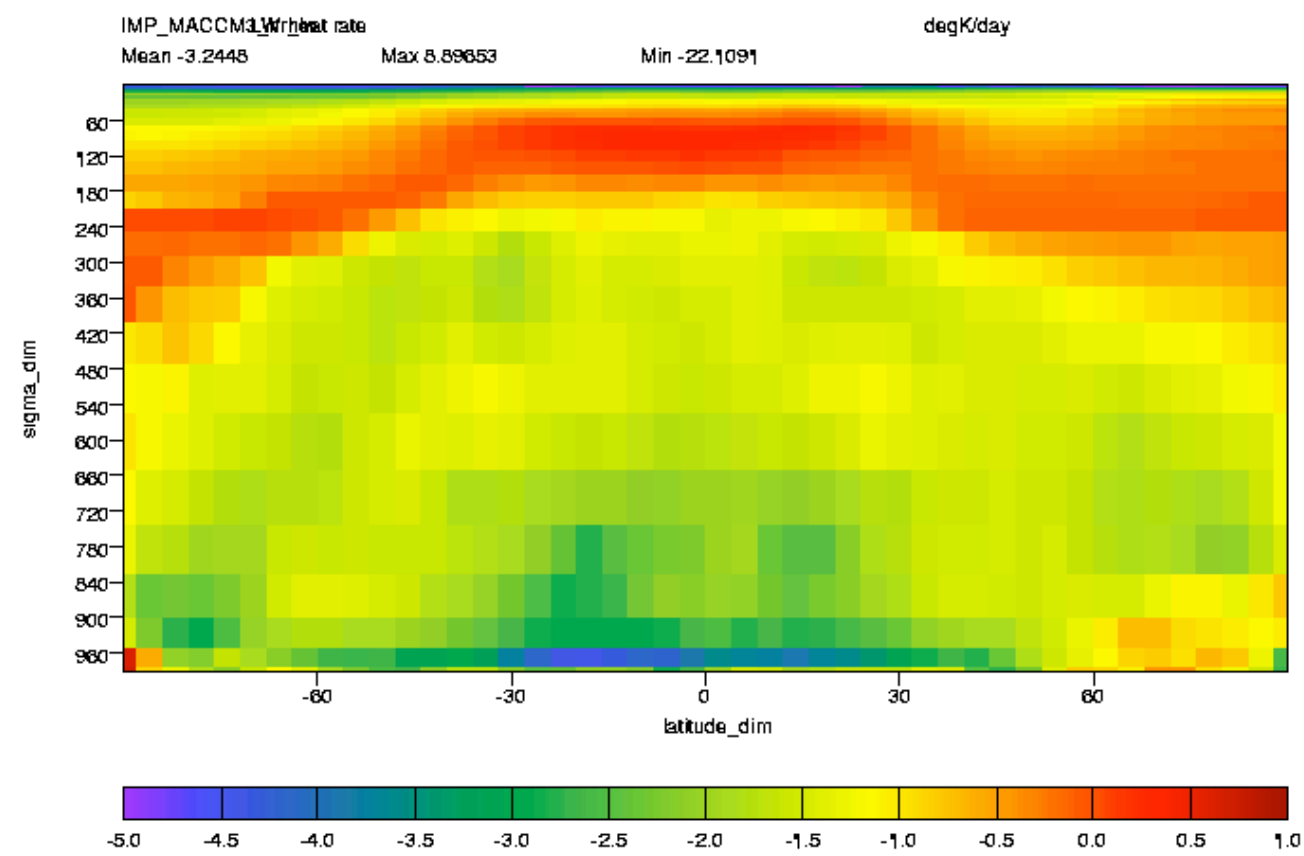

Figure 3.3: IMPACT run with MACCM3, zonally averaged February longwave heating rate, K/day. All three runs (Figures 3.1-3.3) give very similar results. 


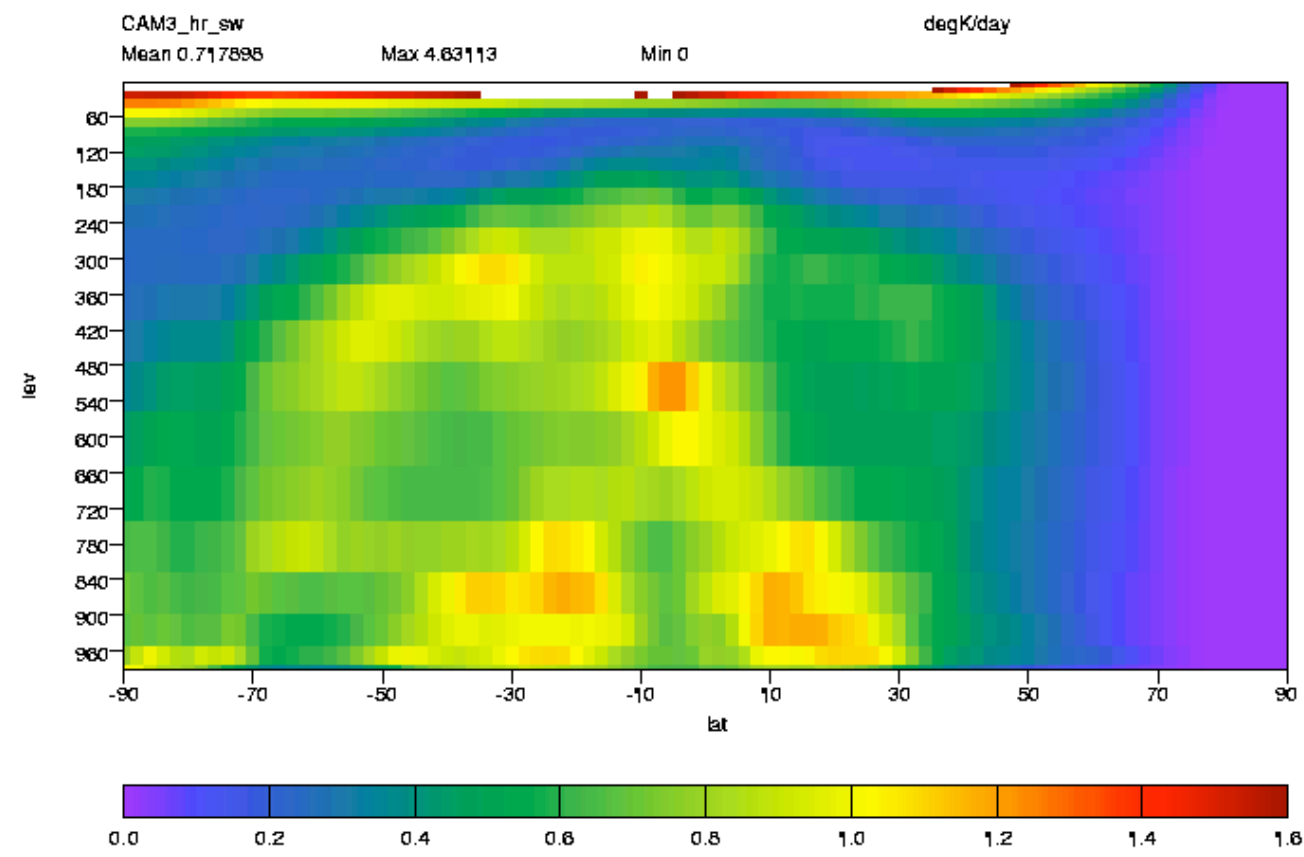

Figure 3.4: CAM3 GCM mean shortwave heating rate for February, zonally averaged, $\mathrm{K} /$ day.

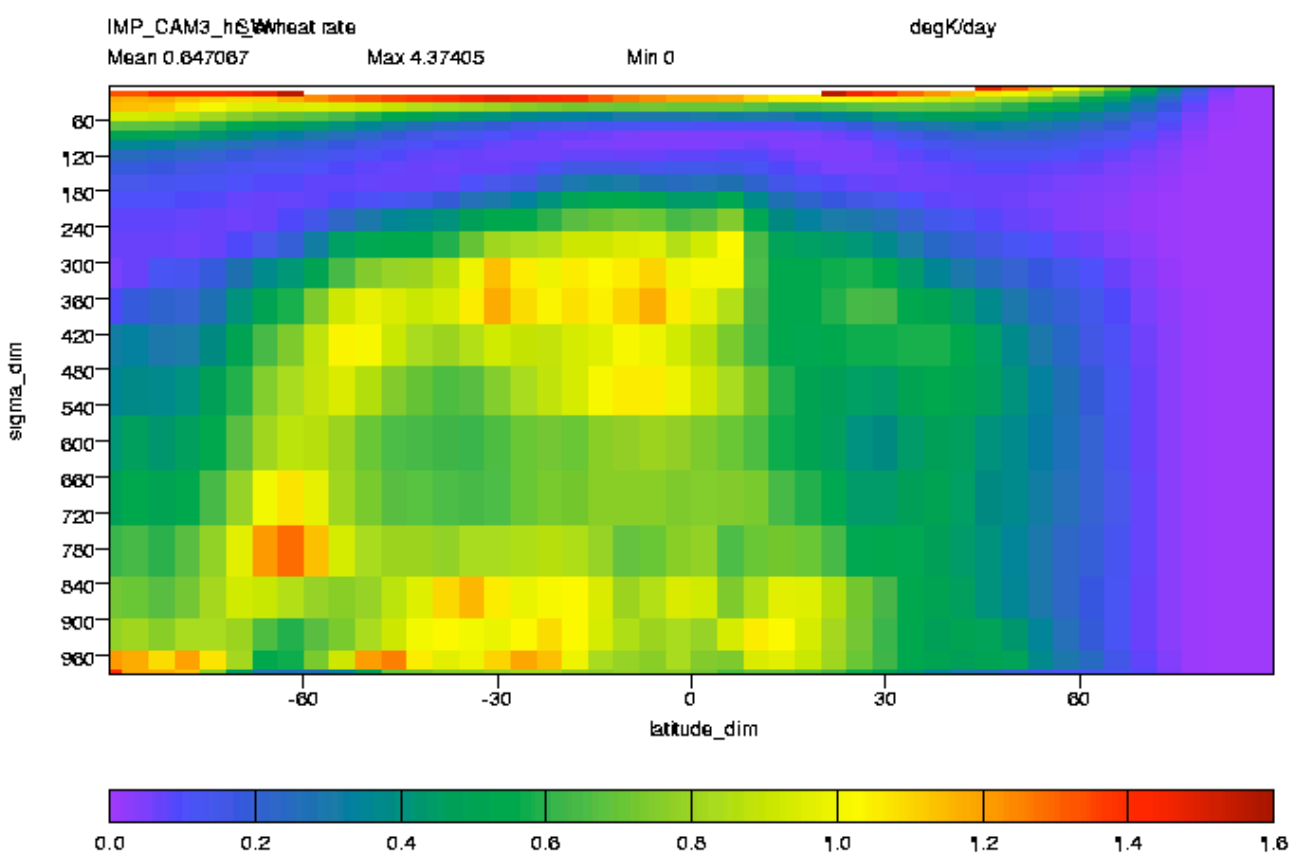

Figure 3.5: IMPACT run with CAM3, mean shortwave heating rate for February, zonally averaged, K/day. Note similarity to Figure 3.4. 


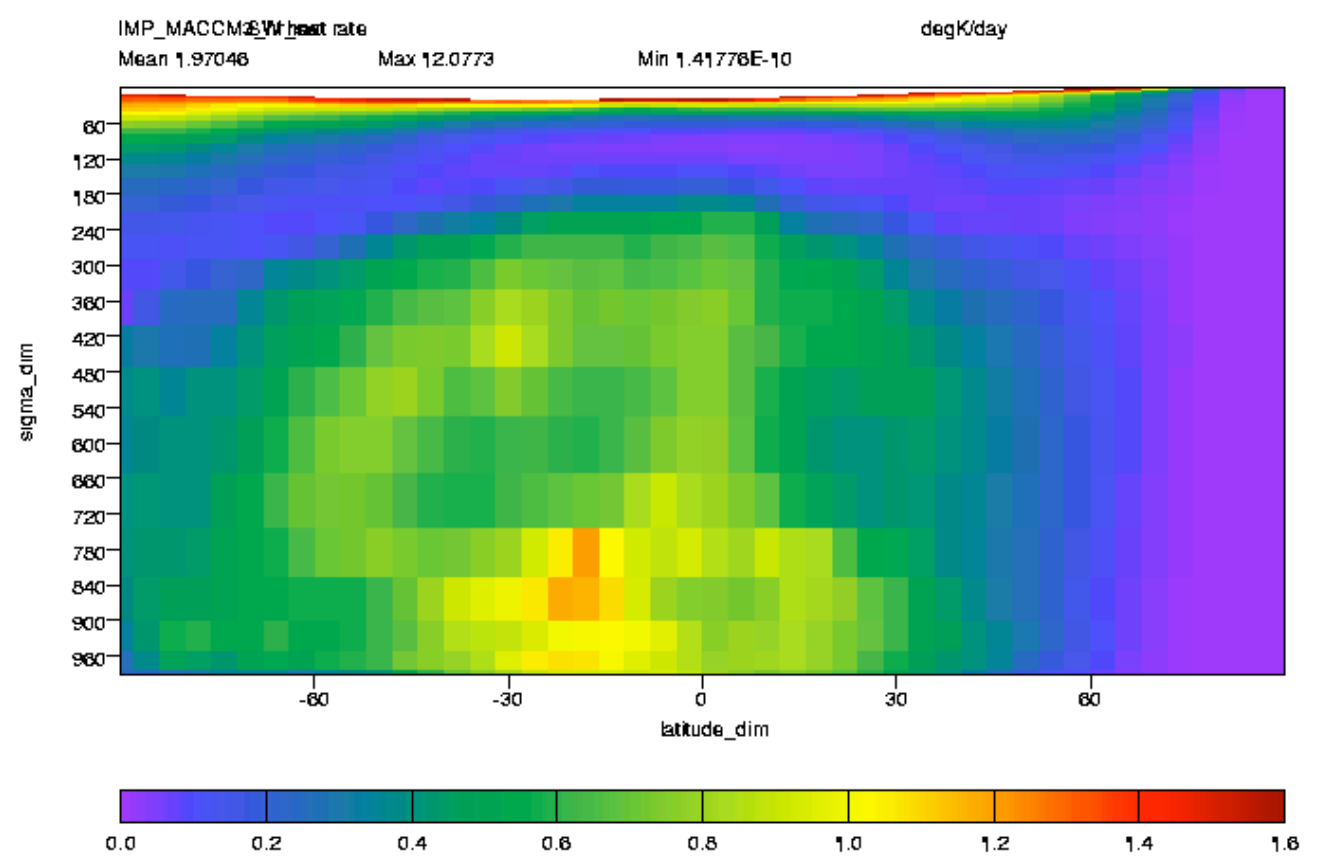

Figure 3.6: IMPACT run with MACCM3, mean shortwave heating rate for February, zonally averaged, K/day. The global mean and maximum values here are higher because of MACCM3's better vertical resolution in the stratosphere.

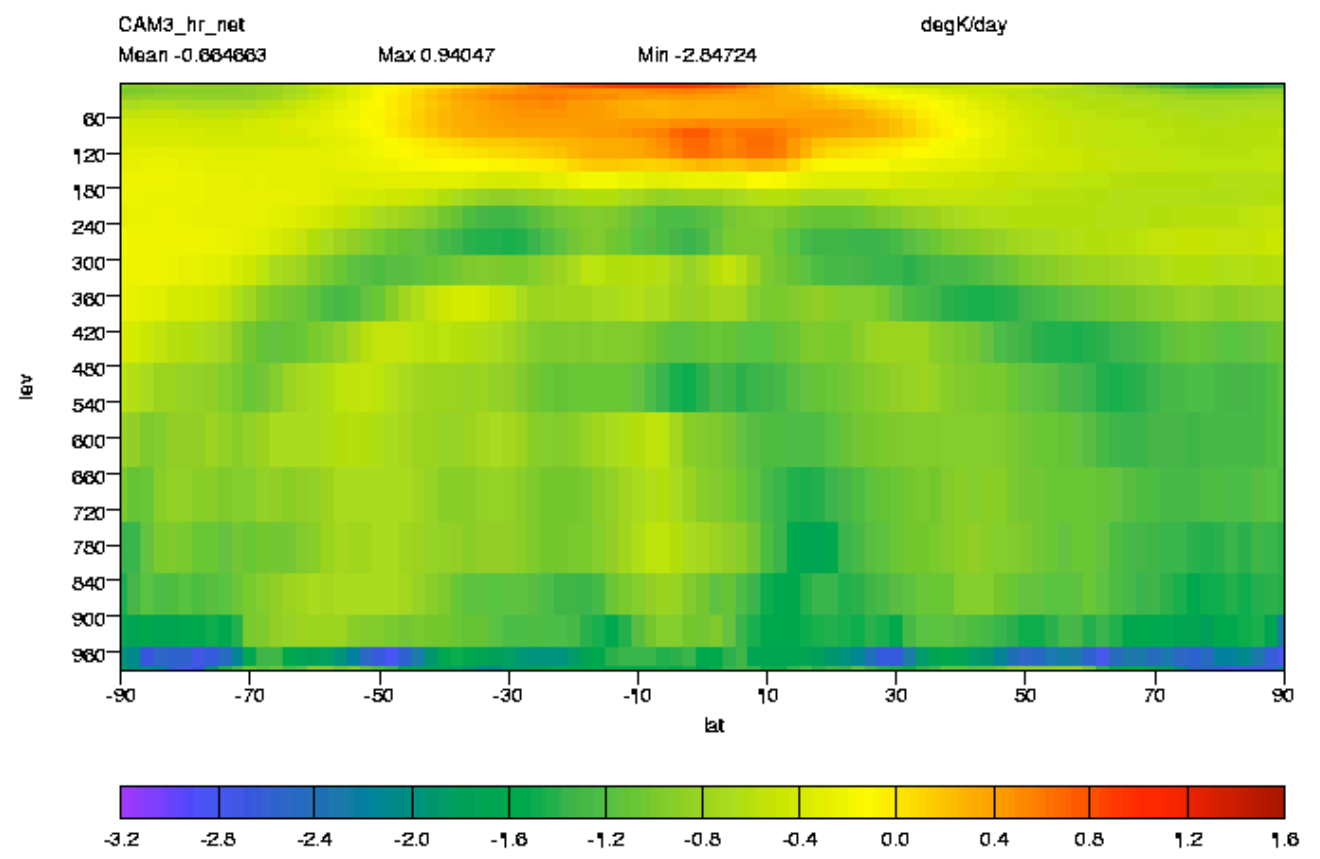

Figure 3.7: CAM3 GCM net heating rate (sum of figures 3.1 and 3.4). 


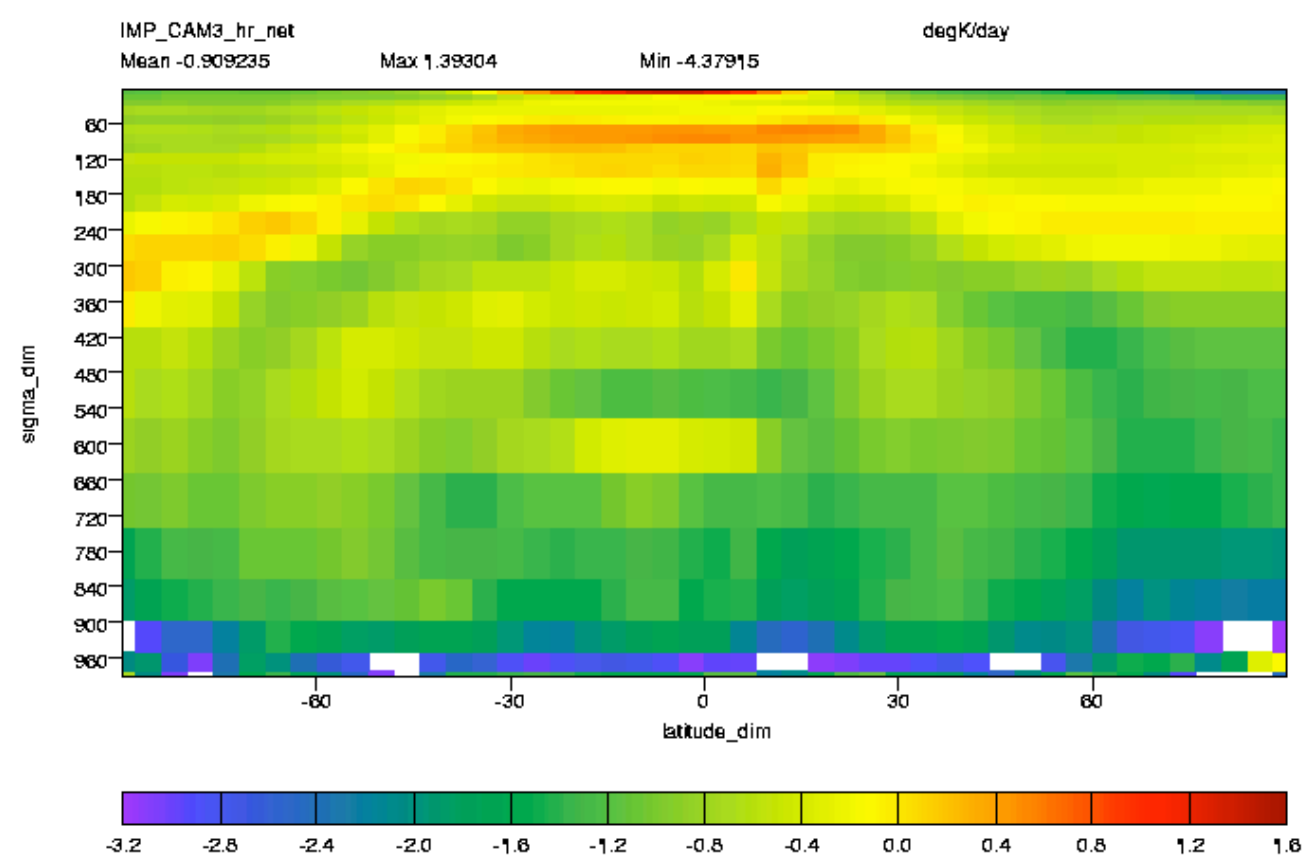

Figure 3.8: IMPACT with CAM3 net heating rate (sum of 3.2 and 3.5).

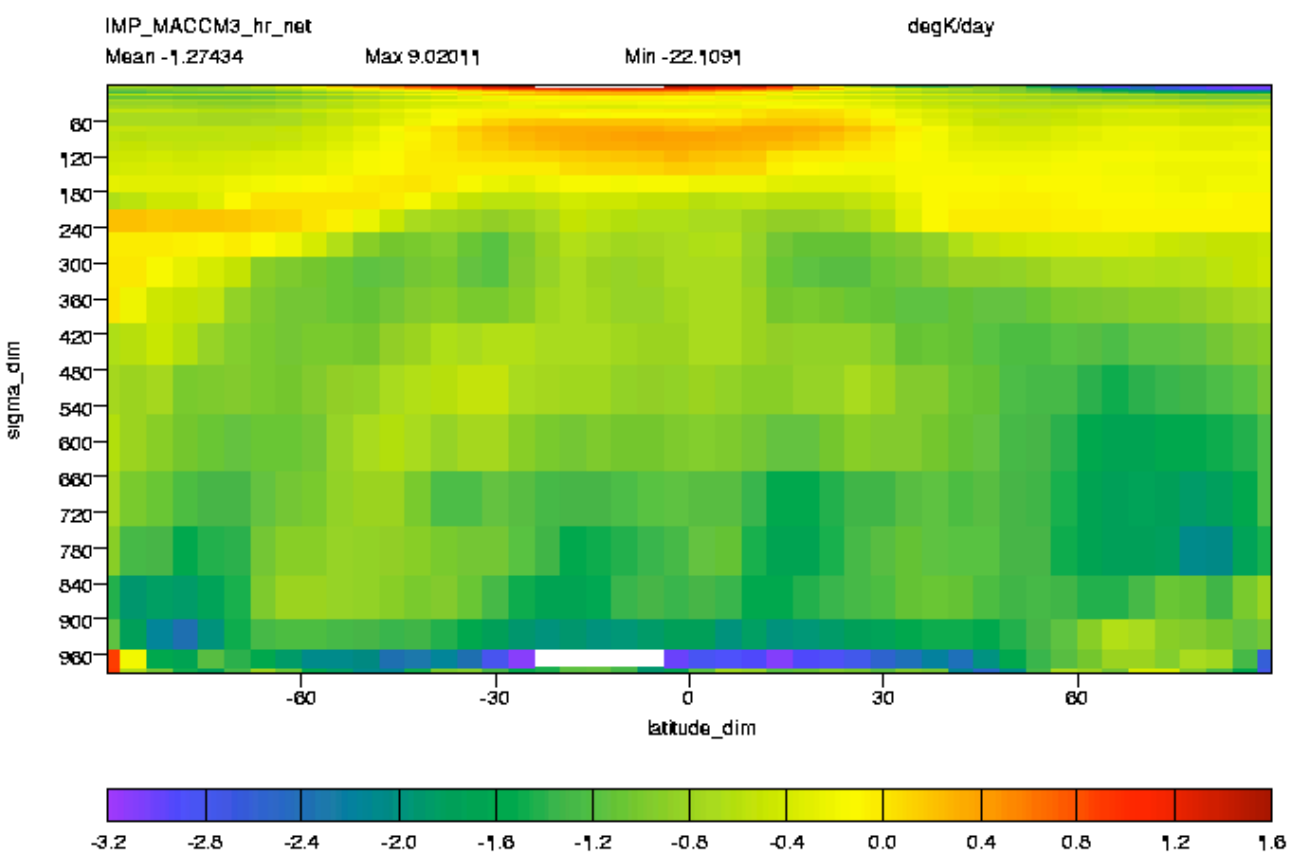

Figure 3.9: IMPACT with MACCM3 net heating rate (sum of 3.3 and 3.6). 


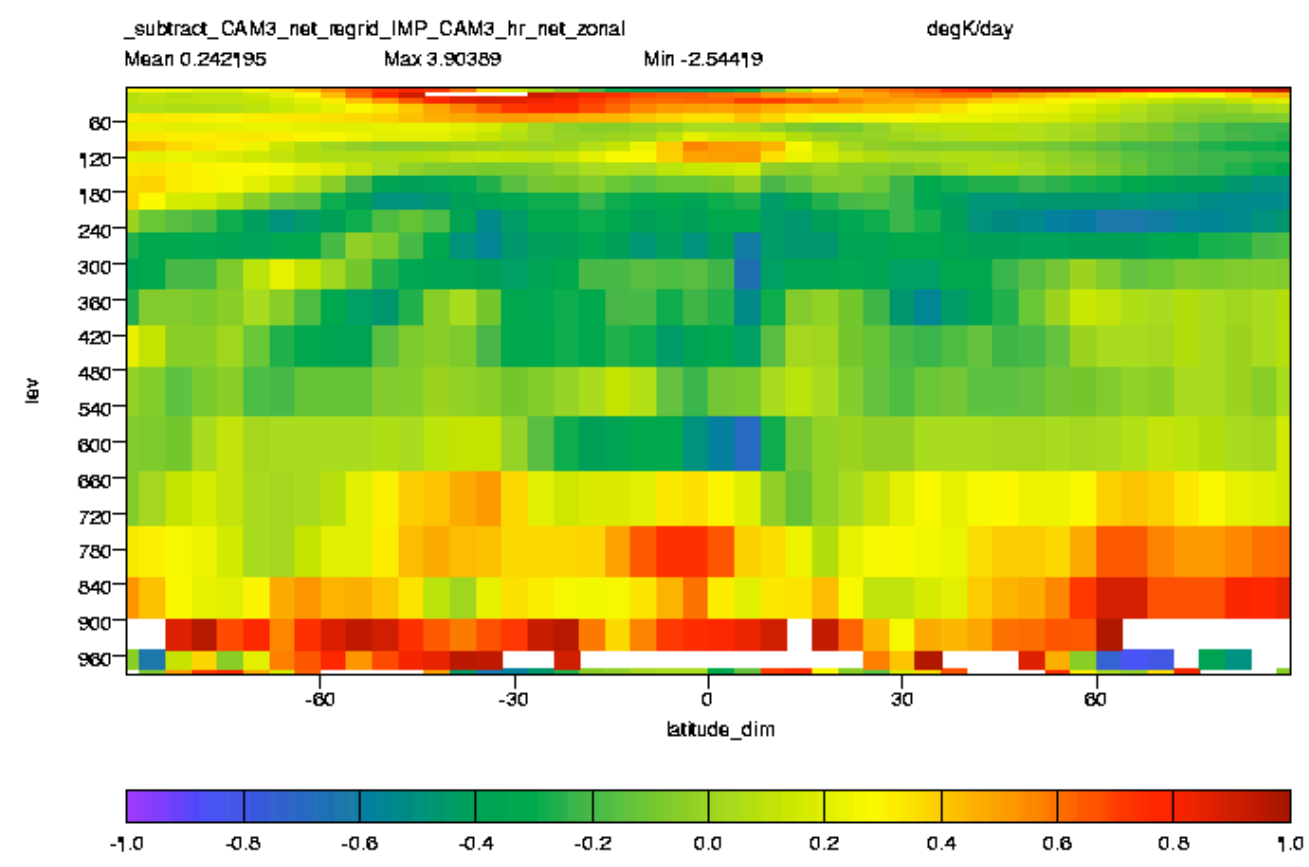

Figure 3.10: The difference between CAM3 GCM and IMPACT running CAM3 met data and clouds (Figures 3.7 and 3.8). The difference is small and scattered; the results appear very close. The off-scale white parts are due to clouds etc. close to the surface.

The comparisons show results that are remarkably close; as close as could be expected given differences in data, methods of calculation, lack of aerosols in the IMPACT CAM3 calculations (TS5) and so forth. This would seem to indicate that the diagnostic radiation code, including the CAM3-based cloud property calculations, is doing its job properly.

\subsection{Surface and Top-of-model Fluxes}

A final set of comparisons were made between the flux data available from the CAM3 GCM, and equivalent quantities calculated for IMPACT running with CAM3. Note that the CAM3 met data used by IMPACT was from a different realization.

The surface and top-of-model values for short and long wave fluxes were available with both. Comparing these showed results that were again very similar in terms of magnitudes and overall pattern. Again, this increases our confidence that the radiation code in IMPACT is working properly. 


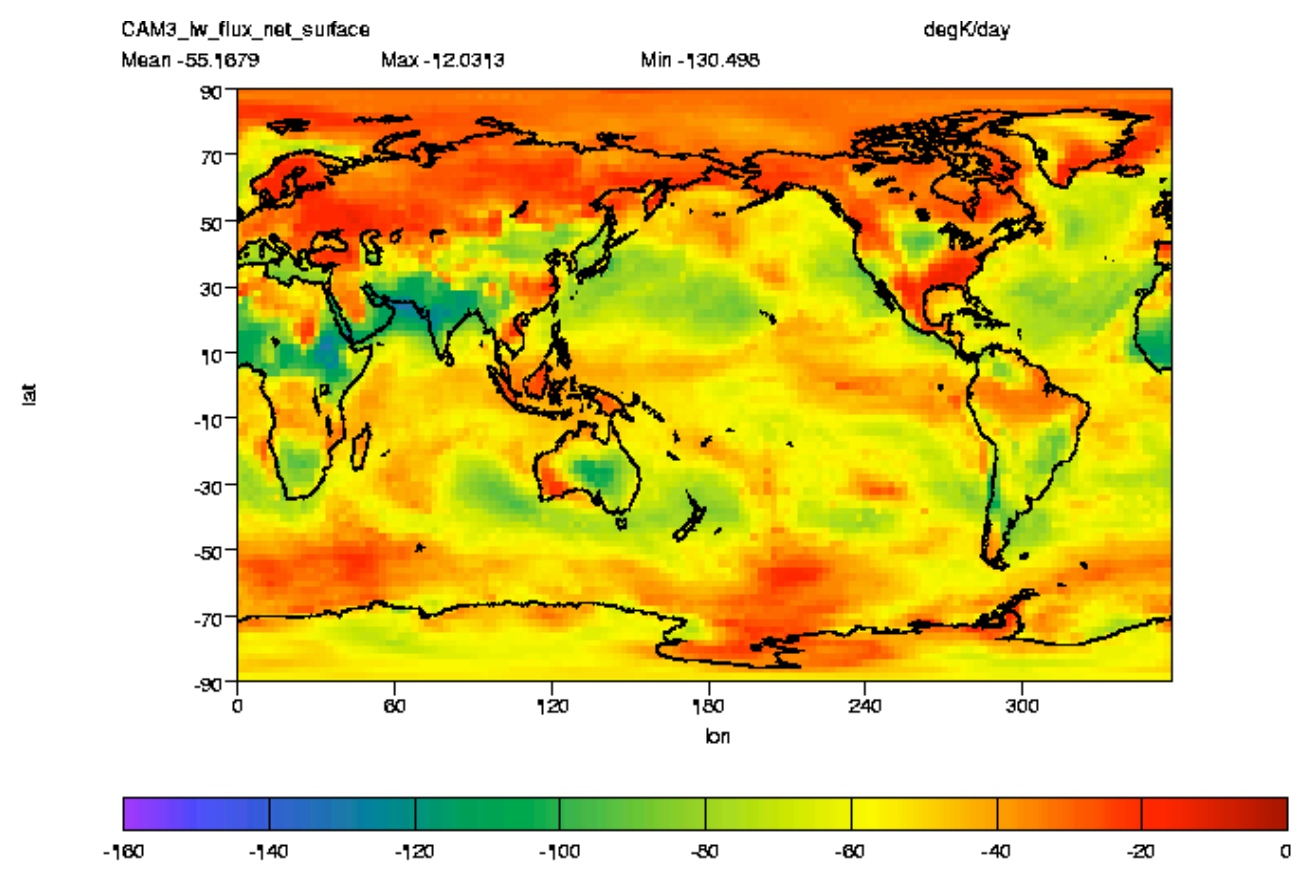

Figure 3.11: Net longwave flux at the surface, monthly mean for February, from the CAM3 GCM. Note that the units should have been printed as $\mathrm{W} / \mathrm{m}^{2}$; vcdat again started acting confused with units at this point.

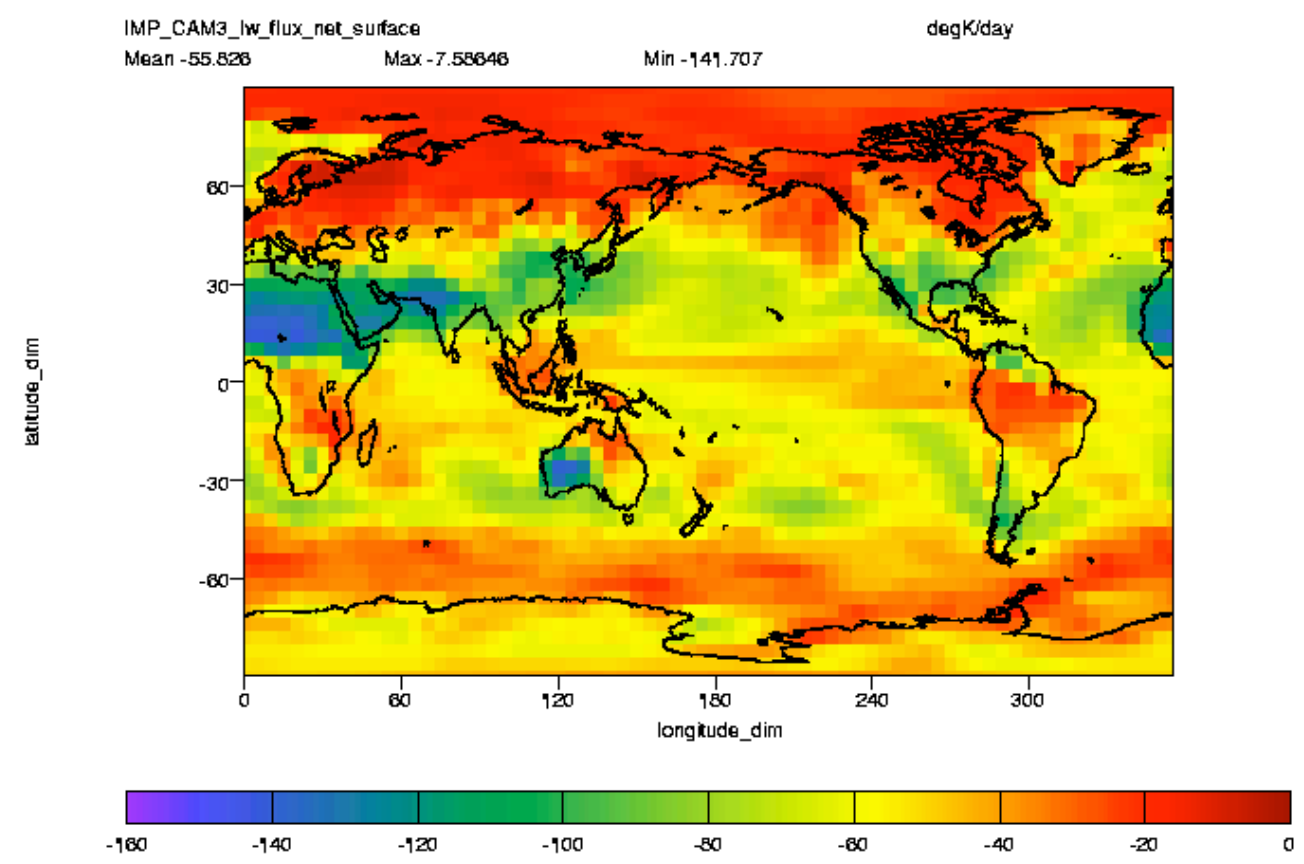

Figure 3.12: The equivalent of 3.11 (net longwave flux at surface) for IMPACT running with CAM3 met data. $\mathrm{W} / \mathrm{m}^{2}$. While very similar to 3.11, differences in Australia and North Africa are noticeable. We do not know of a definite reason, and it does not seem too significant in the context of our comparisons. 


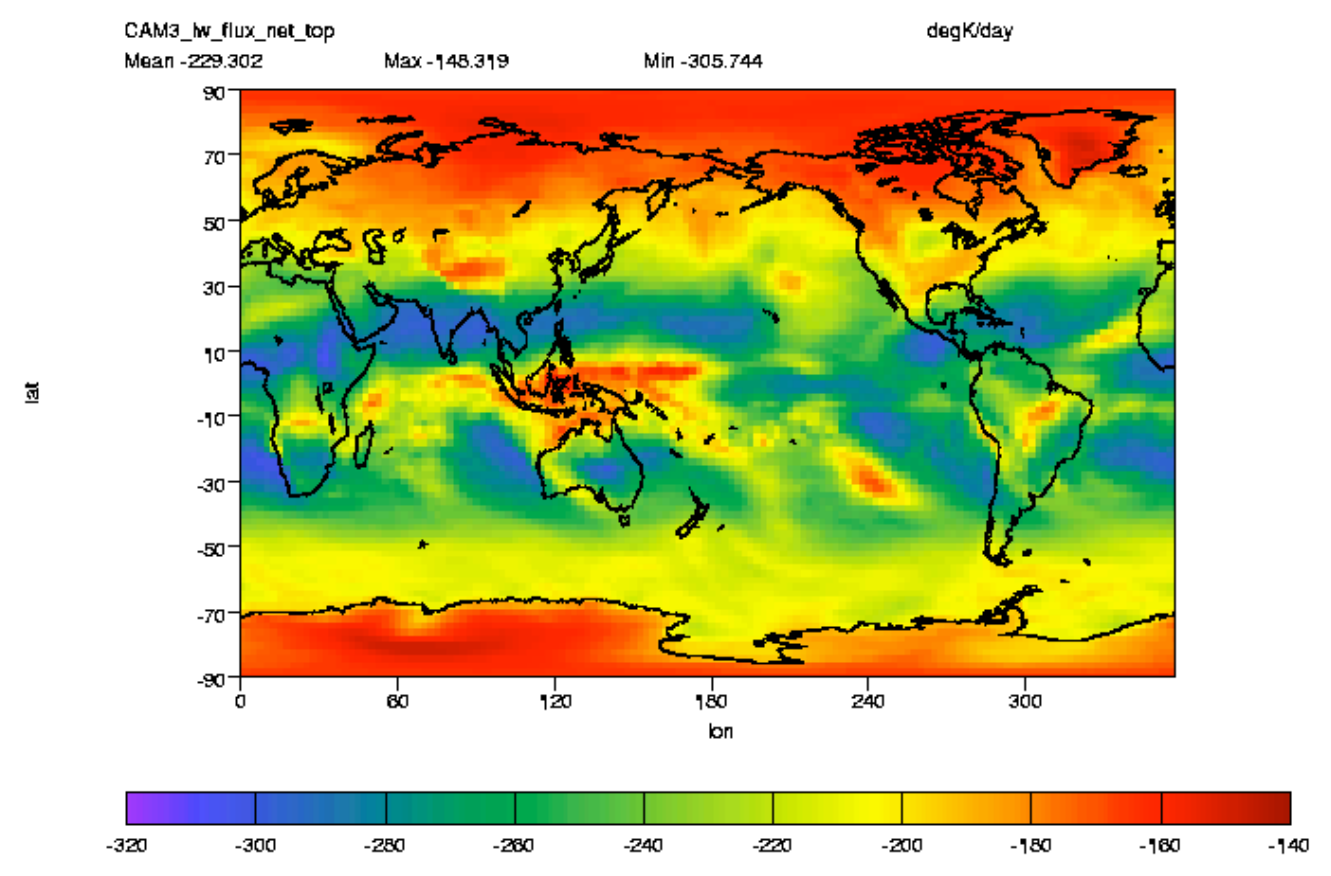

Figure 3.13: CAM3 GCM for longwave net flux at the top of the model; monthly mean for February. Units should be $\mathrm{W} / \mathrm{m}^{2}$.

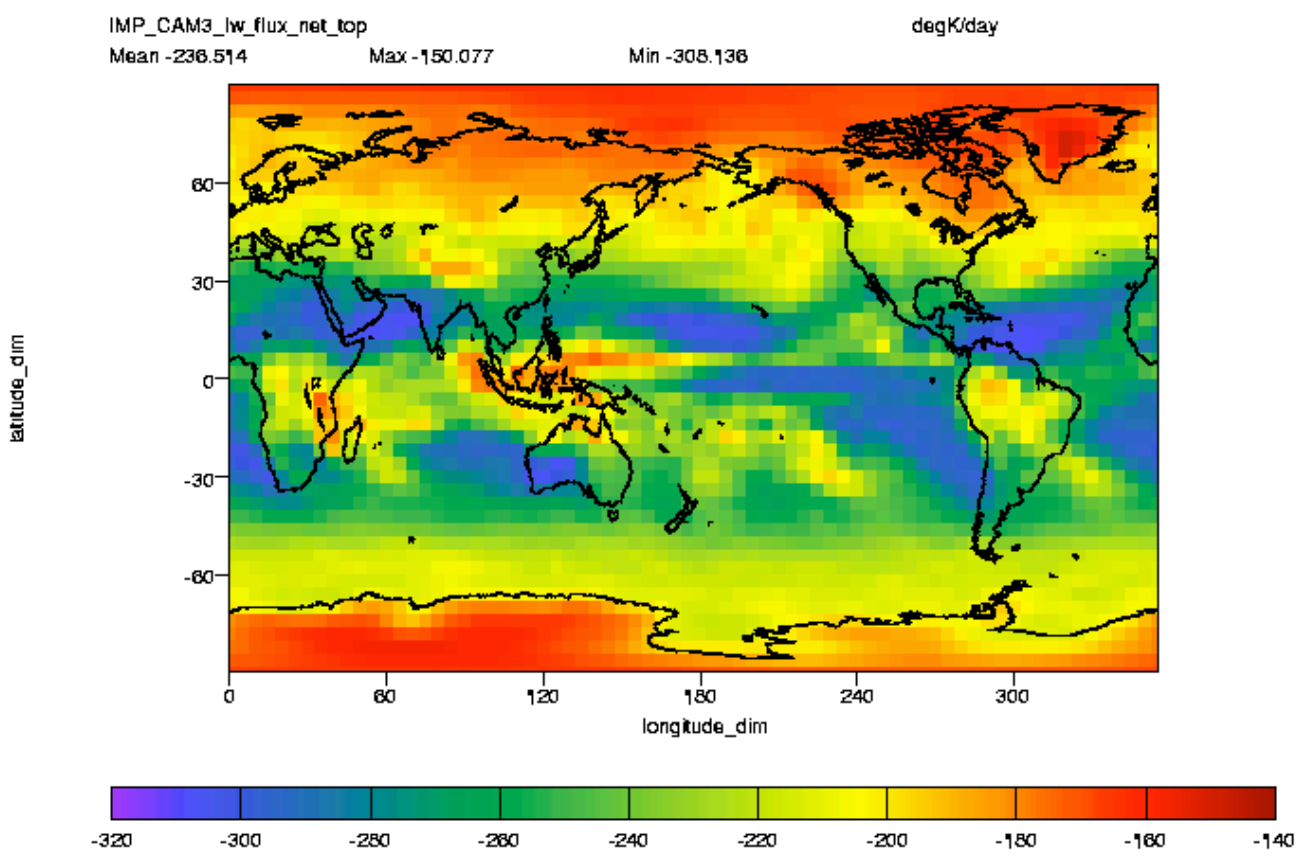

Figure 3.14: The equivalent of 3.13 (net longwave flux at the top of the model) for IMPACT running on CAM3 met data. 


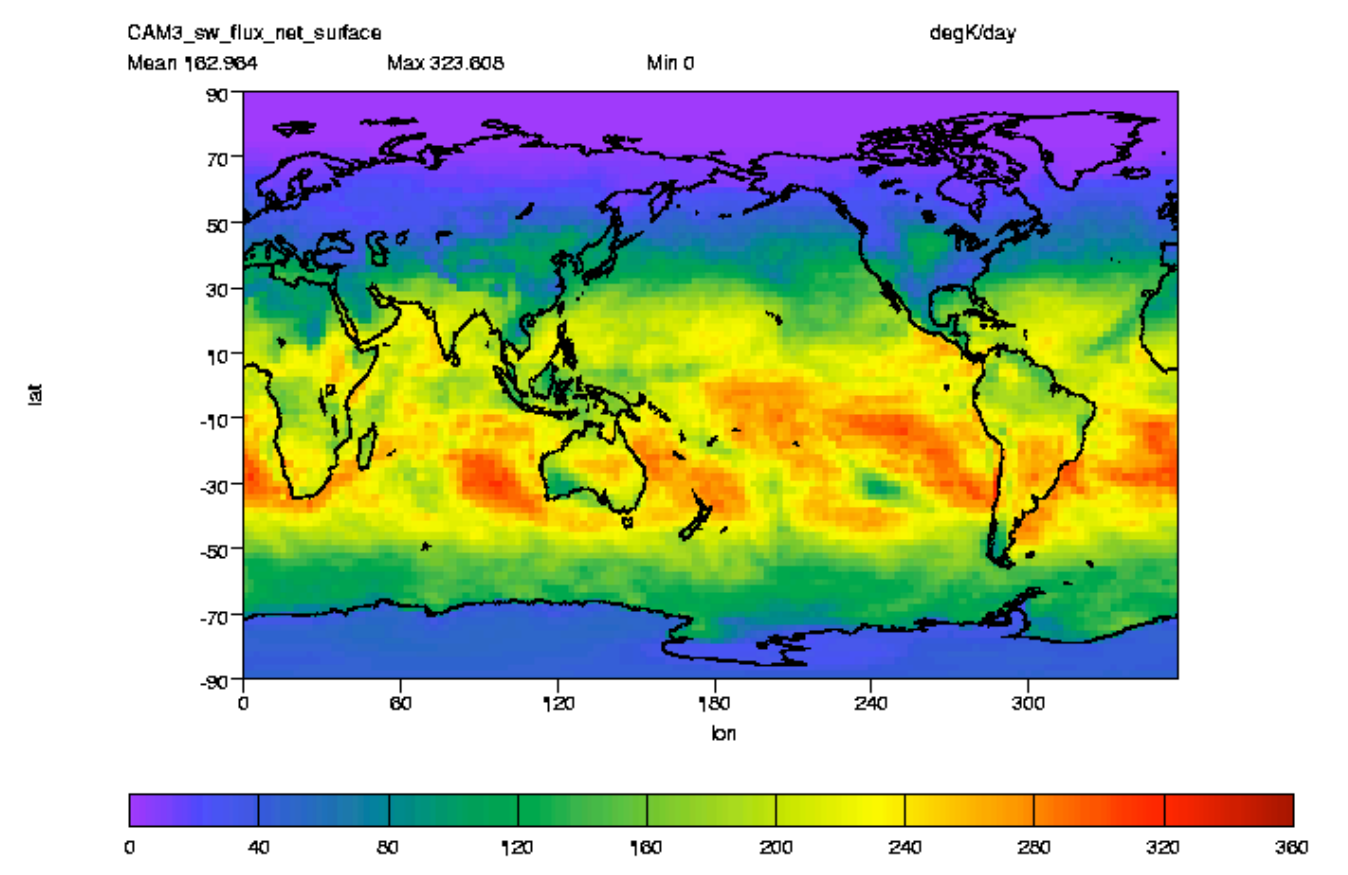

Figure 3.15: CAM3 GCM for shortwave net flux at the surface; monthly mean for February. Units should be $\mathrm{W} / \mathrm{m}^{2}$.

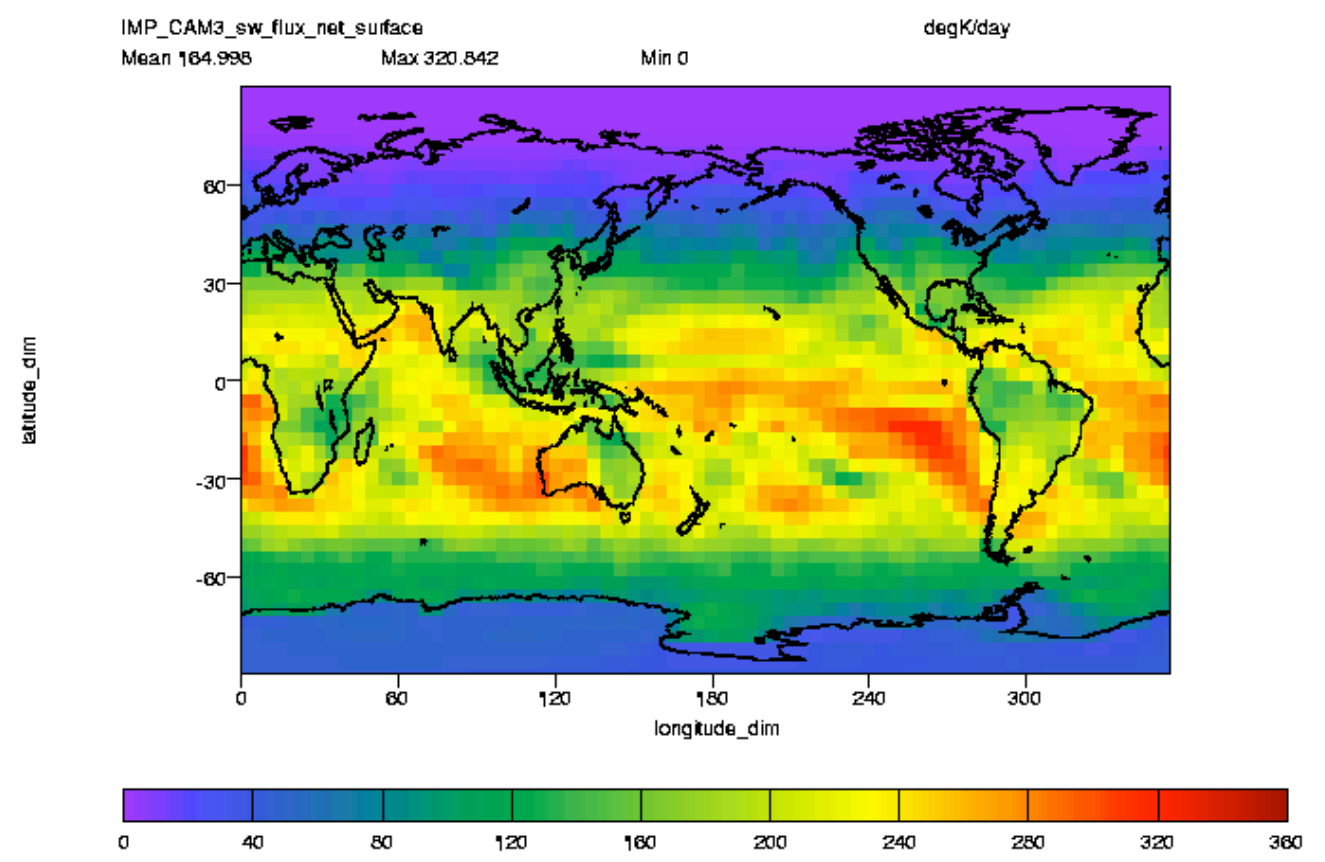

Figure 3.16: The equivalent of 3.15 (net shortwave flux at the surface) for IMPACT running on CAM3 met data. 


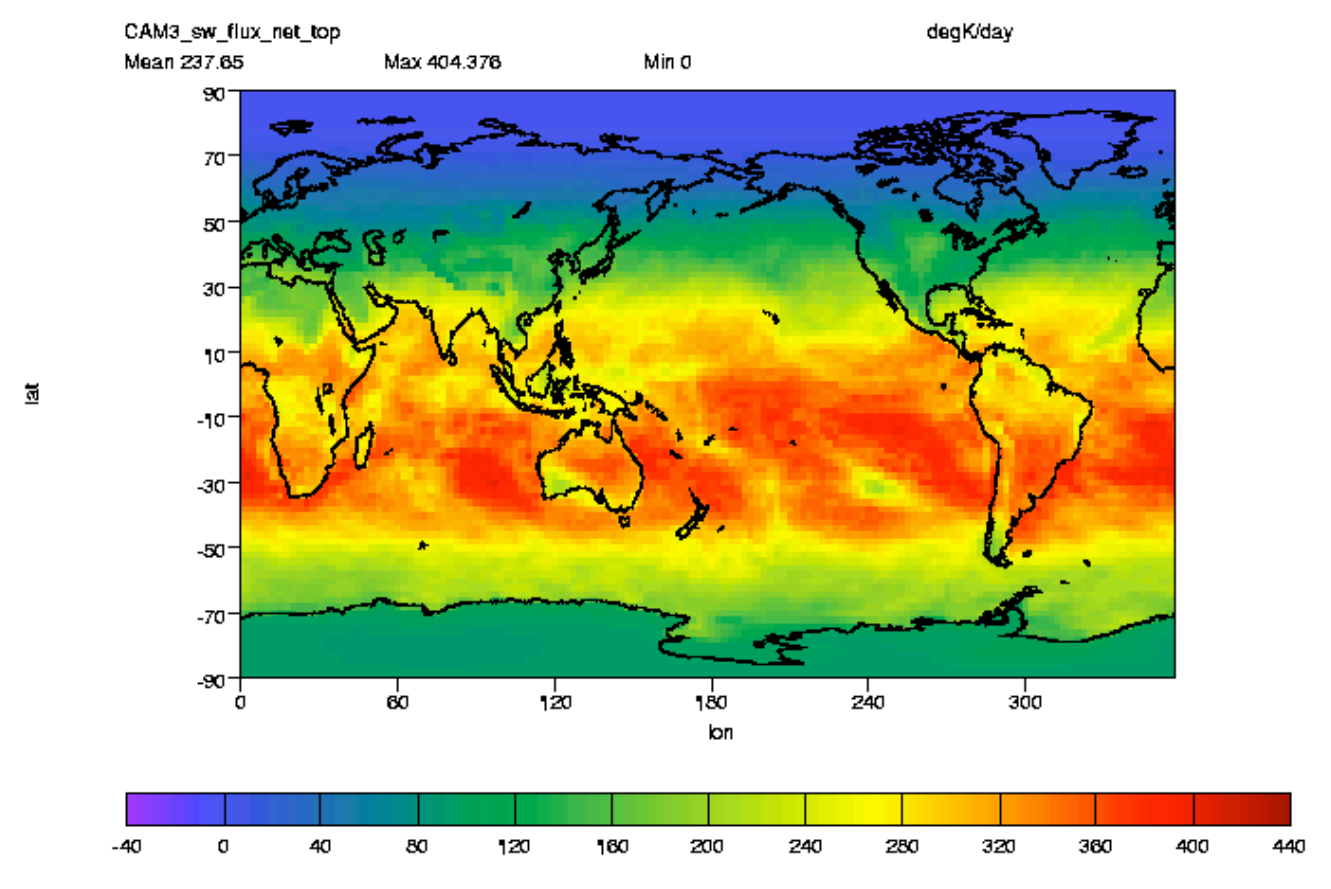

Figure 3.17: CAM3 met data for shortwave net flux at the top of the model; monthly mean for February. Units should be W/m².

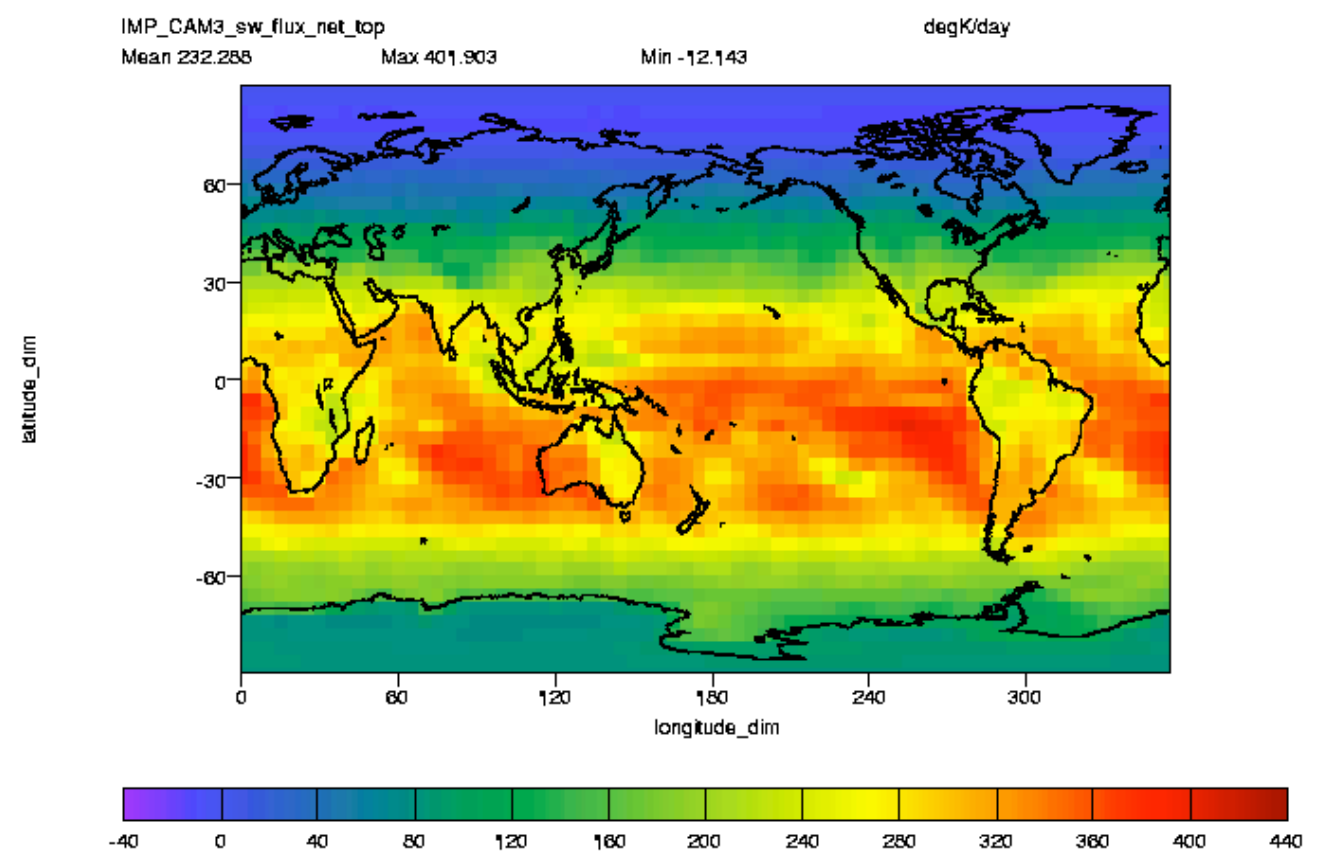

Figure 3.18: The equivalent of 3.17 (net shortwave flux at the top of the model) for IMPACT running on CAM3 met data. 


\section{Conclusion}

The overall purpose of this work was to implement and test changes to IMPACT's radiation routines. Most of these changes were necessary to properly handle cloud optical depths during IMPACT runs with CAM3 met data.

The cloud optical depth parametrization used for CAM3 produces good results when used with CAM3. There are, however, significant differences between the cloud optical depths obtained through this parametrization and others such as the DAO-based optical depths. This highlights the importance of using parametrizations appropriate to particular met data sets.

The heating rates and radiation fluxes produced with the new code running with CAM3 met data look very reasonable. There are some notable features such as the slight extra heating observed in the region of the tropopause, but considering that unlike a GCM, IMPACT cannot adjust the temperature in response to calculated heating rates, these are not entirely surprising.

Overall, it appears that the new modifications to IMPACT's radiation code are working properly, producing acceptable results. 